\title{
Effects of balance transfer offers on consumer short-term finance: evidence from credit card data
}

\author{
Yan Yuan* and Toshiyuki Sueyoshi
}

*Correspondence:
yan.yuan@nmt.edu
Management Department,
New Mexico Institute
of Mining and Technology,
801 Leroy Place, Socorro, NM
87801, USA

${ }^{*}$ Correspondence: yan.yuan@nmt.edu New Mexico Institute 801 Leroy Place Socorro, NM 87801, USA

\begin{abstract}
This research investigates efficiency differences between two important financial approaches that credit card companies use to attract customers. Since the cash-back offer has been already investigated by previous studies, this study focuses upon the balance transfer offer and then compares them in terms of their influences on consumers' short-term finance. The proposed research utilizes the three-stage investigation. The first stage is related to consumers' choice on offers. The second stage estimates the offer's overall and monthly effects on payment, spending, and changes on debt in order to capture consumers' dynamic finance conditions. The last stage estimates the effects on balance transfer and cash-back offers compared with control and nonpromotional finance conditions. This study finds that the balance transfer offer is more effective in making a financial impact to consumers' short-term finance than the cashback offer.
\end{abstract}

Keywords: Balance transfer, Short-term finance, Consumers' choices, Credit card

\section{Background}

Credit cards have been widely used in the USA. The industry has matured so much that most households hold many credit cards and most consumers use credit cards as means of payment. They usually maintain their records on credit cards. In the USA, a total amount of credit card balances is about $\$ 700$ billion. Because of the wide usage of credit cards, the term of cards is becoming a major selling point in addition to some other attractive offers (e.g., balance transfer). Every credit card company tries to offer good terms in many forms to attract more customers and encourage existing customers to borrow more. The credit card company gives offers with different combinations of interest rates and fees with different promotion durations. Under such a business environment, the company raises a business inquiry regarding how consumers response to different offers and what specific components of the offers are.

Providing many attractive offers, credit card companies have a business inquiry regarding how consumers respond to their different contract offers. A number of research efforts previously examined a consumers' choice and an effect of offers. For example, Shui and Ausubel (2004) found that more consumers accepted an introductory offer which had a lower interest rate with a shorter duration than a higher interest

(c) The Author(s) 2017. This article is distributed under the terms of the Creative Commons Attribution 4.0 International License (http://creativecommons.org/licenses/by/4.0/), which permits unrestricted use, distribution, and reproduction in any medium, provided you give appropriate credit to the original author(s) and the source, provide a link to the Creative Commons license, and indicate if changes were made. 
rate with a longer duration. Meanwhile, Agarwal et al. (2006) assessed the rationality by using a credit card experiment dataset, in which consumers made their financial decisions between two contracts with two combinations on annual fees and interest rates. Unfortunately, their studies focused on the type of offers on credit cards. Balance transfer offers were not examined in these studies, but currently becoming a more popular and important issue to credit card companies than before.

Recently, different types of products and offers are proposed along with the development of a credit card market. To maximize the profit, companies are interested in which type of offers can provide an impact on consumers' behavior more and further stimulate them more to borrow money. Jappelli (1990) has discussed who is credit constrained in the U.S. economy and this study could be helpful to credit card companies. Later, Musto and Souleles (2006) used a unique panel dataset of credit bureau records to measure the "covariate risk" of individual consumers and provided insight into the nature of the shocks hitting different types of consumers. Previous studies only analyzed a single type of offers by card companies. For example, Shui and Ausubel (2004) examined the preapproved solicitation offer. Agarwal et al. (2007) analyzed federal income tax rebate to consumers. As an extension of such balance transfer offer analyses, this research investigates business implications by comparing between the cash back and the balance transfer in order to examine which offer is more profitable to credit card companies.

To attain the research objective, this study examines consumer behavior by analyzing the effects of a balance transfer (BT) offered from a credit card company which is often accompanied with consumer's short-term finance. Moreover, comparing between BT offers and cash-back offers, this study attempts to examine a business implication: Which offers are more effective in impacting consumers' short-term finance. To obtain the implication, this study uses a randomized dataset provided by the Royal Bank of Scotland (RBS bank). An important feature of the dataset is that it contains account information both from the specific credit card company (CCC) and from the Equifax (EFX) bureau for every consumer. The EFX bureau is one of the three largest American credit agencies founded in 1899 that reports and maintains credit information on over 400 million consumers worldwide for every corresponding month.

The remainder of this study is organized as follows: Section 2 reviews previous studies on the credit card market and consumers' behaviors. This section also specifies the position of this study by comparing it with the previous studies. Section 3 describes the BT offer and dataset used in this study. The multinomial choice model is utilized in Sect. 4 to measure consumers' choices on the offer. Section 5 estimates the total effect of averaged financial variables from consumers' behavior to the offer. The section also visually describes its monthly paths. Section 6 summarizes estimation results. Section 7 discusses business implications and describes which offer is better for a credit card company in terms of stimulating consumers' short-term finance behavior. Finally, Sect. 8 summarizes this research along with future extensions.

\section{Literature review}

Rationality of consumers' contract choices in various industry activities Hendel (1999) estimated multiple-discrete choice models to computerization returns. Miravete (2003) studied mistakes of consumers when they subscribed to telephone calling plans. Later, 
Narayanan et al. (2007) developed a structural model of the plan choice and usage decisions of consumers to explain their uncertainty regarding mean usage levels, future usage levels, and different rates of learning in two plans. Agarwal et al. (2006) assessed consumers' rationality by using a dataset on credit card experiment. Della Vigna and Malmendier (2006) analyzed a dataset from three US health clubs to find how consumers selected from a menu of contracts among gyms. Laibson et al. (2007) estimated time preferences using a structural buffer stock consumption model and the method of simulated moments and analyzed the choices over the lifecycle. Du and Kamakura (2008) proposed a stuctural demand model to approximate the spectrum of consumption categorues to maximize an underlying utility function to understanding how consumers allocate their consumption budget. Nevo (2011) discussed diffferent models to analyze consumer behavior. Also Papies et al. (2011) analyzed that how consumer choices will be impacted by free ad-funded downloads.

Usage and response of consumers in credit card market Shimp and Moody (2000) provided the theoretical explanation for the credit card effect. Gross and Souleles (2002) analyzed how consumer debt responded to changes in credit supply. They found that an increase in credit limits generated immediate and significant rises in debt, which was inconsistent with permanent-income hypothesis (PIH). ${ }^{1}$ This study also estimated the elasticity of debt to interest rates and found that people were in fact sensitive to interest rates and higher interest rates leaded to substantially less borrowing. As discussed previously, Shui and Ausubel (2004) observed two phenomena which suggested time inconsistency in consumer behavior. One of the two phenomena was that more consumers accepted an introductory offer which had a lower interest rate with a shorter duration than a higher interest rate with a longer duration. The other phenomenon was that consumers were reluctant to switch. The authors analyzed a credit card dataset and used a hyperbolic discounting model to rationalize observed behavior of consumers. Besides such previous studies, Agarwal et al. (2007) examined how consumers responded to the 2001 federal income tax rebate, which was regarded as the "lumpy" increase. They suggested that on average, consumers initially saved some amount of their income tax rebates and used it to increase their credit card payments, so paying debt down. Soon afterward, consumers' spending was increased. It is widely known that the use of tax rebates is important economic behavior for every household. After they started the interesting point of "lumpy" tax rebates, Gross et al. (2012) studied how the 2001 and 2008 tax rebates affected consumer bankruptcy filings.

Motivation of consumers and other intents to any offer Back to 1991, Ausubel (1991) pointed that the failure of the competitive model $^{2}$ appeared to be partly attributable

\footnotetext{
${ }^{1}$ The hypothesis implies a theory of consumption that assumes rational behavior by consumers. It states that a change in permanent income, rather than a change in temporary income, affects their choices that determine consumer's consumption patterns. Bar-Ilan and Blinder (1988) discussed the permanet-income model.

2 The competitive market model consists of scarce resources and two types of agents, consumers and firms. A resource is an item (or service) which is valued by agents in economy. Since it is scarce, there is never enough of the resource to satisfy all the agents all the time. For this reason, allocation decisions must be made. The agents come together at a market, where they buy or sell resources. In the competitive market, prices are adjusted until supply equals demand. At this price, the market is in equilibrium. A perfectly competitive model would at least predict zero long-run economic profits for "marginal" firms. Moreover, since free entry into the industry is possible and no input appears to be in scarce supply, there is no credible source of rents to distinguish "inframarginal" firms from "marginal" firms. Thus, the competitive model would predict that all credit card issuers earn zero in their long-run economic profits.
} 
to consumers making credit card choices without taking account of a very high probability that they would pay interest on their outstanding balances. Calem and Mester (1995) analyzed consumer behavior and found the explanation of stickiness on the credit card and interest rates to be imperfect competition in the credit card market. Hendel and Lizzeri (1999) analyzed the adverse selection in durable goods market. Ausubel (1999) first discussed the adverse selection in the credit card market. Calem et al. (2006) also discussed that the adverse selection of a credit card explained persistence of credit card interest rates at relatively high levels. Elaydi and Harrison (2010) examined different motivations behind a careful choice. Scholnick et al. (2013) found that low income individuals made financial mistakes when their decisions were difficult and rare.

It is clear that consumers' choice and behavior are impacted by their motivations and intentions and consumers are assumed to be rational. Therefore, some irrational behavior of consumers can be explained by different motivations and intentions. For example, consumers should borrow less through an offer with higher interest rates. If the consumers have highly borrowing behavior with high interest rates offer, they may be high-risk borrowers and banks may face an adverse selection problem.

Position of this study This research is interested in the BT offer effect to consumers and attempts to compare the two types of offers (i.e., BT offer and cash back) in a credit card market. Since the cash-back offer has been examined in previous studies, this study focuses upon the BT offer and compares it with the cash-back offer. This research is different from the other previous contributions in terms of the three concerns. First, the BT is a special offer that is different from regular credit card offers. Some studies have assessed the estimation with respect to decision of contracts with different introductory interest rates and different duration periods, as found in Shui and Ausubel (2004). However, the BT offer needs to incorporate two more parameters besides a promotional interest rate (PR) and a promotional duration (PD) used in the previous studies. The additional two parameters are a fixed-for-life interest rate (FFL) and a maximum fee. As a result of the additional two parameters, this study can measure their decision making of consumers that have more options on credit cards. Second, consumers' behavior and their choices are related to each other. For example, if consumers only want to enjoy a low interest rate benefit of the BT offer, they choose PR offer because it has the lower interest rate than FFL and pay off the debt before the end of promotion. If consumers have a budget constraint, they cannot pay off their debt at the end of promotion. Therefore, they prefer FFL offer to enjoy the benefit without a limitation of promotion duration. This study implements the analysis considering both consumers' choices (e.g., which offer they select or reject) and consumers' behaviors (e.g., how to use their choices for debt payment or spending). Finally, this study attempts to investigate which strategy is more effective on impacting consumers' finance conditions. No research has examined this type of offer and compared two types of offers by credit card companies. Consequently, it is expected that the empirical results obtained this study will be able to guide credit card companies in preparing business rules and further improving their profitability measures. 


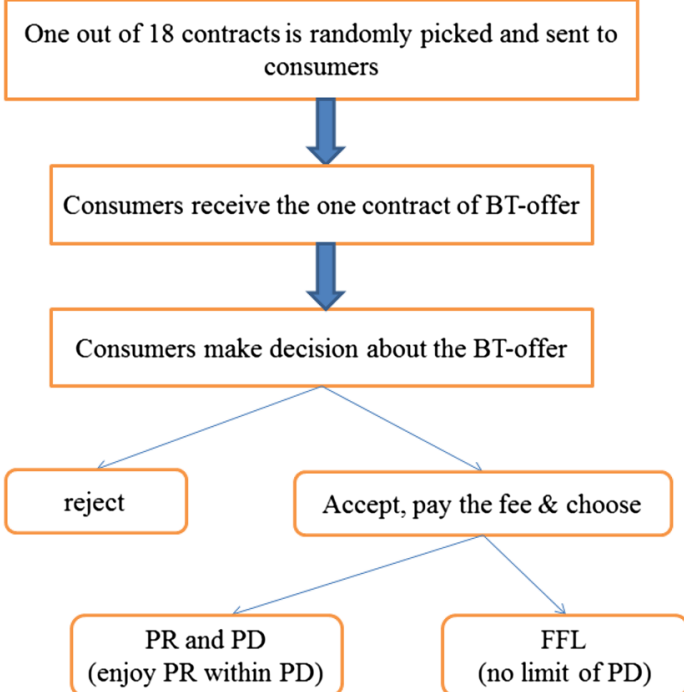

Fig. 1 BT offer procedure. (a) The detail on 18 contracts is listed in Table 1. (b) BT balance transfer, PR promotional rate (\%), FFL fixed-for-life rate (\%), PD promotional duration (months). (c) If a consumer decides to accept the offer, fee listed in contract should be paid and two different options are available. PR is usually lower than FFL. However, the PR option is limited in PD. After determining PD, a consumer should pay his regular purchase rate around $12-20 \%$. On the other hand, the consumer can enjoy FFL without any period limitation. The consumer can choose both options only if the sum of borrowed balances is within his credit limit

\section{Research issue and data}

First of all, abbreviations used in this section are additionally summarized as follows: FFL: fixed-for-life rate, ID: identification, PB: protected balance, PD: promotional duration, PR: promotional rate, and LCH/PIH: life-cycle hypothesis ${ }^{3} /$ permanent-income hypothesis.

\subsection{Balance transfer (BT) offer}

It is widely known that credit card companies send out millions of BT offers in order to encourage more customers to borrow more. BT offers are made to existing customers and sent out as checks. Figure 1 visually describes such a procedure of BT offers for consumers.

Let us introduce the BT offers, first. These offers made by the company characterized by four parameters: by FFL (\%), by PR (\%), by the one-time maximized BT fee, and by PD (months). Each offer is represented by a BT offer ID. The credit card company randomly selects a BT offer ID for every customer regardless of credit card usage, characteristics, or credit history. Then, the company mails the corresponding BT offer to customers.

Table 1 summarizes combinations among four contract parameters whose selection has been determined by a credit company. When customers receive a BT check, they can write an amount on the check as high as a certain fraction of their credit limit and can cash the check at any bank. Thus, the BT offer is essentially an additional loan

\footnotetext{
${ }^{3}$ The hypothesis implies that individuals both plan their consumption and savings behavior over a long term and intend to consider their consumption in the best possible manner over their entire life periods. The key assumption is that all individuals choose to maintain their stable lifestyles.
} 
Table 1 Contracts with detailed information on parameters

\begin{tabular}{llllll}
\hline ID & Contract parameters & ID & Contract parameters & ID & \multicolumn{2}{c}{ Contract parameters } \\
\hline A1 & $(0,3.99,6,75)$ & B1 & $(0,2.99,12,60)$ & C1 & $(0,2.99,6,0)$ \\
A2 & $(0,4.99,6,60)$ & B2 & $(0,2.99,12,75)$ & C2 & $(0,3.99,6,0)$ \\
A3 & $(0,4.99,6,75)$ & B3 & $(0,3.99,12,60)$ & C3 & $(0,4.99,6,0)$ \\
A4 & $(1.9,4.99,6,60)$ & B4 & $(0,3.99,12,75)$ & C4 & $(1.9,4.99,6,0)$ \\
A5 & $(1.9,4.99,6,75)$ & B5 & $(1.9,4.99,12,60)$ & C5 & $(1.9,5.99,6,0)$ \\
A6 & $(1.9,5.99,6,60)$ & B6 & $(1.9,4.99,12,75)$ & C6 & $(2.9,5.99,6,0)$ \\
\hline
\end{tabular}

This table reports the detail of 18 contracts examined in this paper. In parentheses of contracts, four parameters listed are PR, FFL, PD, and one-time maximized BT fee, where $P R$ promotional rate, FFL fixed-for-life rate, and $P D$ promotional duration. The fee indicates the maximized amount of fee for borrowing money

Eighteen contracts are divided into the three groups as A, B, and C according to PD and fee. Group A is a baseline group. Groups $B$ and $C$ are more attractive offers to consumers than $A$ because $B$ has longer PD than $A$ and $C$ has zero in fee, so outperforming A, respectively. For example, A1 has PD is 6 (months) and B1 has PD is 12 (months). A1 has the maximum amount of fee is $\$ 75$ and $C 1$ has the maximum fee is $\$ 0$

extended to existing consumers at an interest rate that is much lower than the usual "purchase" rate ${ }^{4}$ that accrues on the customer's credit card during an introductory and promotional period. Customers can use the check to make purchases that increase their consumptions or use the check to pay off a balance from another credit card. Paying off debt is why the loan check is called a "balance transfer" check, but the use of this loan is applied in many ways.

The composition of two interest rates on the BT offers made by the credit card company is FFL and PR, indicating that there are two options for customers who decide to accept a BT offer.

- The more commonly chosen option is a PR contract whereby customers pay very low or zero interest on the BT amount for PD with 6, 9, or 12 months when they pay off the debt. After the PD ends, however, the remaining transferred balance is added to the rest of the customer's balance and begins to accumulate interest with a much higher purchase rate.

- The second option available to customers is a FFL contract where the BT loan accumulates interest at a FFL rate, which is higher than the PR rate, but lower than the regular purchase rate. However, the advantage of FFL is that the rate stays flat perpetually in principle.

In order to enjoy the benefit, consumers cannot make any mistake under both contract options. If the customer makes any "mistake" on the credit card account such as making a late payment, then the interest rate advantages of the BT offer end. Moreover, the transferred balance is automatically added to the regular balance and begins accumulating interest at much higher purchase rate.

\subsection{Data}

The randomized dataset was obtained from RBS bank, starting in January 2005. Six months later, this credit card company gave different BT check offers to existing

\footnotetext{
4 The purchase rate is usually about $12-20 \%$ from different types of credit cards according to the standard of the credit company.
} 


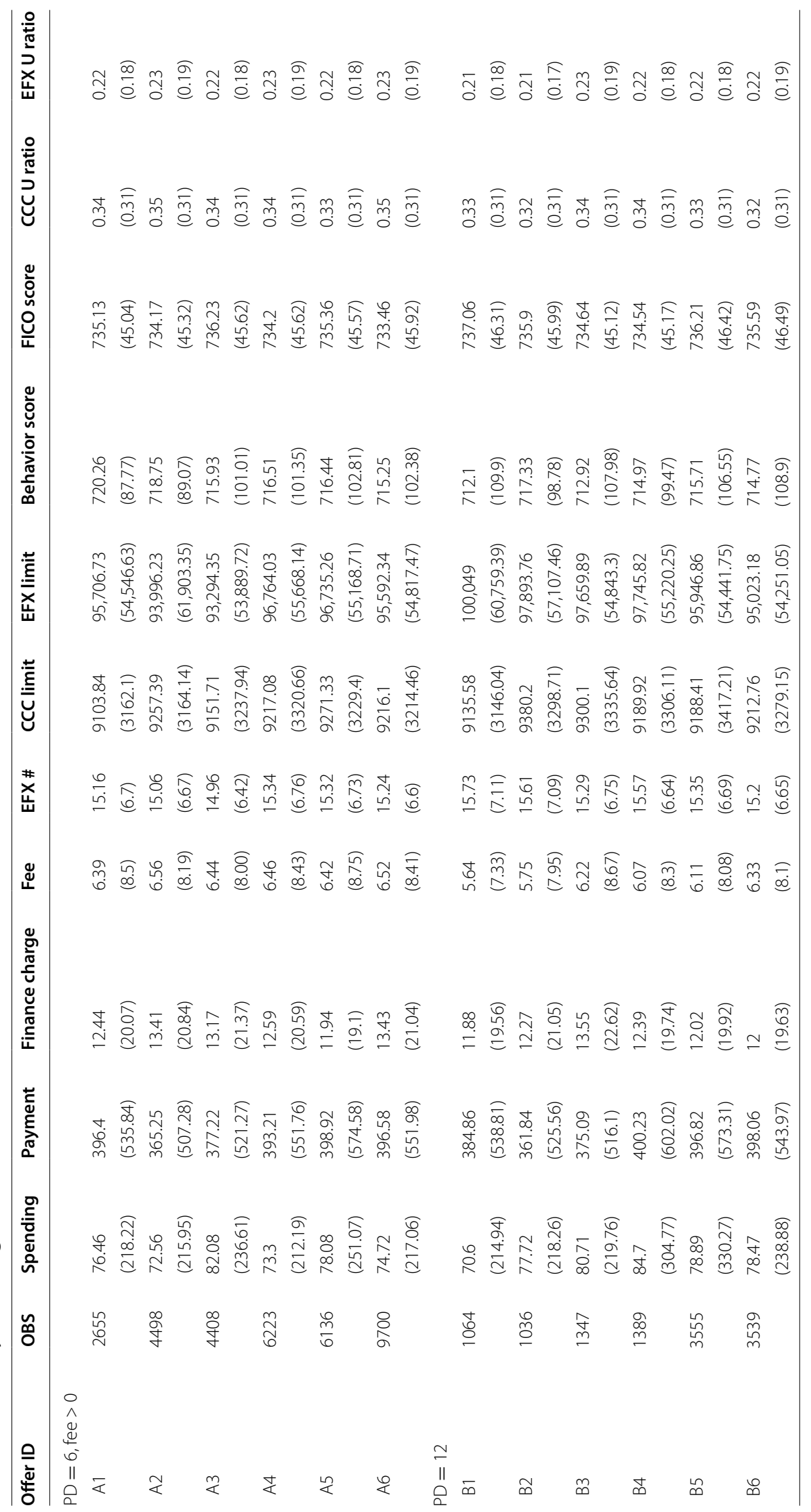




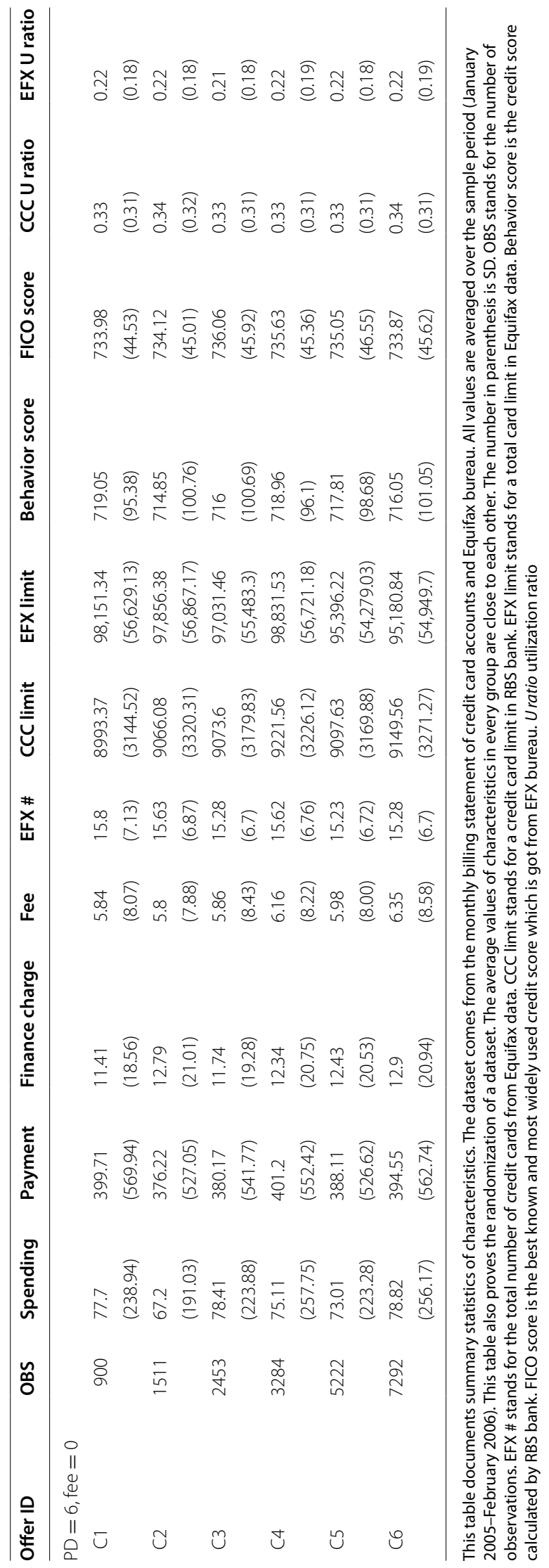


customers and then kept track of the performance of all consumers for 8 months until February 2006, after the campaign. The BT check offer took effect in the seventh month, so that the data before offer receipt were referred to as "historical data" and the data from the seventh month was called "performance data." Besides the historical and performance datasets, a response dataset was available, indicating whether a consumer accepted the offer or not. If the BT offer was accepted, which contract (i.e., FFL or PR) the consumer accepts, how many times consumers borrowed by using PR or FFL contract, and how much they borrowed from the bank through different types of checks and so on. The dataset had not only the account information at the firm level but was also linked with the Equifax bureau. The availability of both firm-level and industrylevel datasets helped us in better understanding on the campaign effect in and out of the credit card company.

The random dataset contained a sample of 66,222 experienced cardholders. The PD was 6 or 12 months. It was expected that the customer would pay off their debt in different months if he/she had different offers with different PD.

The dataset has a number of additional research advantages. The data are very large, and it helps us in examining the dynamics of consumers' response because of the data covers many months. However, there are some disadvantages and limitations on these data. First, because every customer actually may have at least one account in a bank, this study analyzes every credit card account but not every individual. Therefore, this study describes customers instead of account holders. Second, another limitation is that the datasets regarding income or other assets and total spending are not available to us. Response to the offer is highly related to every cardholder's income level. Furthermore, an empirical bias may exist if analyzing the internal spending in one bank instead of total spending to examine the effect. Finally, the performance data only last for 8 months, and there are BT offers with PD for 12 months. Even though the data cannot cover the whole promotion, a dynamic trend of effect of BT offer to consumers' behavior can be used to infer the effect of BT offer with PD for 12 months.

Table 2 uses randomization of the dataset. The table documents descriptive statistics of data characteristics (i.e., the number of observations and the average of variables along with SDs) in 18 BT offers from both firm-level data and Equifax data.

This study separates the dataset into three offer groups (A, B, and C) for controlling for PD and for a one-time maximized BT fee. The basic contract offer Group A is constructed with PD for 6 months and positive one-time BT fee (it could be $\$ 60$ or $\$ 75$ ). The other two contract offer groups (B and C) are constructed as one with PD for 12 months and the other with PD for 6 months and a zero one-time BT fee, respectively.

Figure 2 describes how such three offer groups examined in this study. Three groups are divided by the following two steps.

Step 1 This study first divides the offers by PD. Then, the offers are divided into Group A ( $\mathrm{PD}=6$ months) and Group $\mathrm{B}(\mathrm{PD}=12$ months). The classification is two rationales. One of the two rationales is that interest rates (PR and FFL) are key parameters in this study because FFL contract is not limited by PD. The other is that consumers tend to behave according to $\mathrm{PD}$, especially before the end of promotion. Considering that the effect of BT offer to consumers' behavior may vary with 6- or 12-month duration, this study considers that the 12-month duration offer should be divided into a new group, so preparing the Group B. 


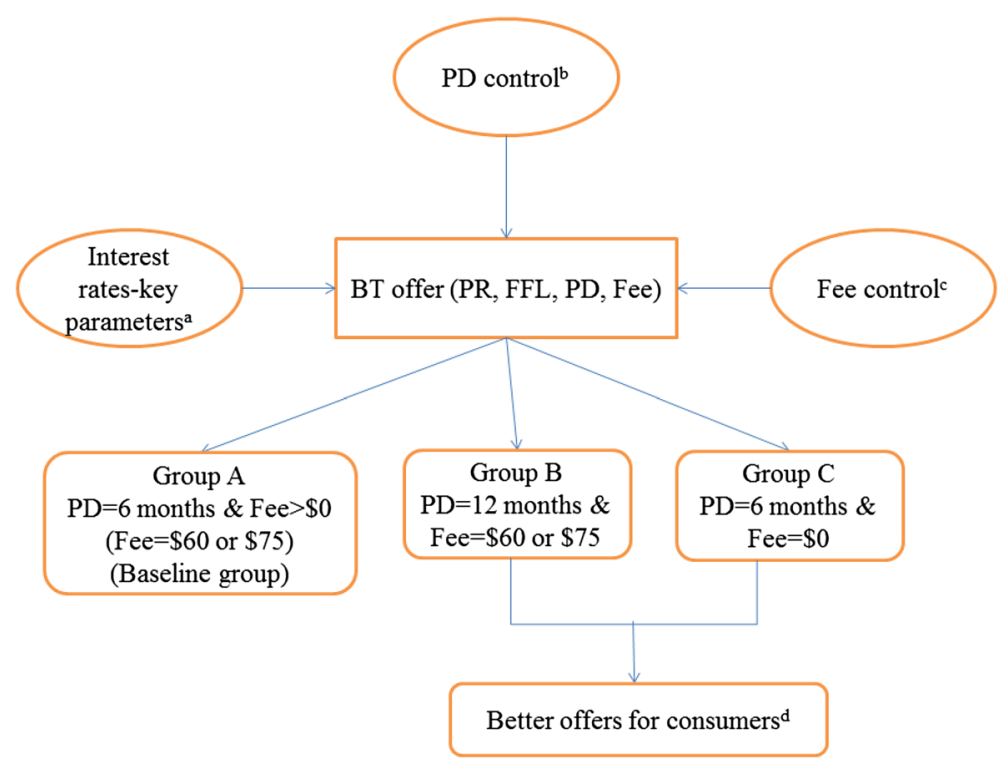

Fig. 2 BT offer groups. (a) BT balance transfer, PR promotional rate (\%), FFL fixed-for-life rate (\%), PD promotional duration (months). (b) The short-term finance (payment, spending, and $\Delta$ debt) is not significantly impacted by PD and fee. $\Delta$ debt represents the difference of debt between every 2 months. Debt is a stock variable that is accumulated balance after BT campaign. Thus, $\Delta$ debt is the new debt level in every month, which is used as a dependent variable in this study. There are three types of debt, later, in this study: (1) $\triangle C C C$ balance which represents the change of balance in RBS bank. (2) $\triangle E F X$ balance represents the change of balance from Equifax bureau. (3) $\triangle P B$ balance represents the change of balance with high interest rates calculated by RBS bank itself. Therefore, two interest rates are key parameters for this study. (c) Consumers tend to behave according to different lengths of PD, especially at the end of PD. Thus, the BT offer with $P D=6$ months and PD $=12$ months is separated in this study. (d) The offers with PD $=12$ months only contain fee $=\$ 60$ or $\$ 75$. The offers with PD $=6$ months contain fee $=\$ 0$ or $\$ 60$ or $\$ 75$. Then, the offers with $\mathrm{PD}=6$ months and fee $=\$ 0$ are separated out in order to compare effect of offer at the same level of fee. (e) Comparing the baseline Group A, Group B contains offers that have longer PD with the same fee. Group C contains offers that have fewer fees with the same PD. Therefore, Groups B and C are better than Group A in terms of offers for consumers

Step 2 This study divides the offers by the one-time maximum BT fee. In addition to Group A ( $\mathrm{PD}=6$ months and fee $=\$ 60$ or $\$ 75)$ and Group B (PD $=6$ months and fee $=\$ 60$ or $\$ 75)$, this study considers Group $C(P D=6$ months and fee $=\$ 0)$. The rationale and process for Group $C$ are summarized as follows: The one-time maximized BT fee could be 0,60 , or 75 dollars in Group A with 6-month duration offers, while in Group B with the 12-month duration, the one-time BT fee could only be 60 or 75 dollars. To find the effect of PD and fee to consumers, one of PD and fee should be controlled when the BT offers are compared. Therefore, the Group $C$ with 6 months and zero BT fee is further separated from Group A. The rest of Group A is the final Group A with 6 months and positive BT fee. As mentioned in Fig. 2, this study considers that offers in Group B with a longer duration or those in Group C with a less (zero) one-time BT fee are better offers for consumers.

To capture an expansionary impact of the BT offer, this research is interested in the response of spending, payments, and debt, all of which serve as dependent variables. Spending and payment are flow variables ${ }^{5}$ that represent the amount of spending and 
Table 3 Take-up rate for three groups

\begin{tabular}{|c|c|c|c|c|c|c|c|c|}
\hline \multicolumn{3}{|c|}{ Baseline group $(A)(P D=6$, fee $>0)$} & \multicolumn{3}{|c|}{ Offer group $(B)(P D=12)$} & \multicolumn{3}{|c|}{ Offer group $(C)(P D=6$, fee $=0)$} \\
\hline \multicolumn{2}{|c|}{ Offer ID } & \multirow{2}{*}{$\begin{array}{l}\text { Take-up } \\
\text { rate (\%) }\end{array}$} & \multicolumn{2}{|c|}{ Offer ID } & \multirow{2}{*}{$\begin{array}{l}\text { Take-up } \\
\text { rate (\%) }\end{array}$} & \multicolumn{2}{|c|}{ Offer ID } & \multirow{2}{*}{$\begin{array}{l}\begin{array}{l}\text { Take-up } \\
\text { rate (\%) }\end{array} \\
30.78\end{array}$} \\
\hline A1 & $(0,3.99,75)$ & & B1 & $(0,2.99,60)$ & & $\mathrm{C} 1$ & $(0,2.99,0)$ & \\
\hline $\mathrm{A} 2$ & $(0,4.99,60)$ & 9.54 & B2 & $(0,2.99,75)$ & 24.52 & $\mathrm{C} 2$ & $(0,3.99,0)$ & 24.49 \\
\hline A3 & $(0,4.99,75)$ & 8.98 & B3 & $(0,3.99,60)$ & 20.42 & C3 & $(0,4.99,0)$ & 19.73 \\
\hline A4 & $(1.9,4.99,60)$ & 6.64 & B4 & $(0,3.99,75)$ & 19.58 & $\mathrm{C} 4$ & $(1.9,4.99,0)$ & 12.85 \\
\hline A5 & $(1.9,4.99,75)$ & 6.18 & B5 & $(1.9,4.99,60)$ & 10.38 & $\mathrm{C} 5$ & $(1.9,5.99,0)$ & 11.32 \\
\hline A6 & $(1.9,5.99,60)$ & 6.13 & B6 & $(1.9,4.99,75)$ & 9.35 & C6 & $(2.9,5.99,0)$ & 9.41 \\
\hline
\end{tabular}

The numbers in parentheses are contract parameters listed as PR, FFL, PD, fee, where $P R$ promotional rate, $F F L$ fixed-for-life rate, and $P D$ promotional duration (months). The table reports the take-up rates for three different groups after BT offer campaign (August 2005-February 2006)

Once the consumer transferred one amount of money, he will be regarded as taking up the offer. From the table, the take-up rates (in second, fourth, and sixty columns) increase when interest rates decrease, PD increases, and fee decreases. And the take-up rates of two better offers are nearly triple the take-up rates of Group (A) for good contracts with $0 \%$ PR and low FFL. Even for bad contracts (contracts $A 5-C 5$ and $A 6-C 6$ ) with high interest rates, the take-up rates are nearly double. For example, the take-up rate for contract $\mathrm{C} 5$ is $11.32 \%$, and it is $6.18 \%$ for $\mathrm{A} 5$

payment in every month, and they can be directly linked to the proposed analysis. Meanwhile, the debt contains the following three types of debt in this study:

- The specific credit card company (CCC) balance, which is the debt for the credit card company.

- The Equifax (EFX) balance, which is the aggregate debt for all banks.

- The protected balance (PB), which is the debt carrying a high interest rate and may earn more profit for the credit card company.

The three types of debt, specified above, are stock variables ${ }^{6}$ that are accumulated balances after the BT offer campaign. The changes in debt are used as dependent variables to maintain potentially persistent offer effects on debt. Among them, the EFX balance is the most important variable to which this study pays attention because consumers not only make purchases by using BT checks, but pay off debt from another credit card that carries a higher interest rate. The actual change of a debt level can only be reflected by the EFX balance. Due to the limitation of our dataset, this study can use the change of EFX balance to reflect a total amount of consumption by consumers even though we do not have a dataset for a total amount of purchase. This study also focuses upon CCC balance and purchases.

Finally, this study has two research concerns to be examined. One of the two concerns is that Group B is compared with Group A to find the effect of PD on consumers' behavior at the same level of BT fee. The other concern is that Group C is compared to Group A to find the effect of one-time BT fee on consumers' behavior at the same level of PD. In other words, how consumers respond to better offers is evaluated and it helps credit card companies to design different types of offers. Within every group, we are interested in examining how consumers' short-term finance is impacted by BT offers characterized by two interest rates. No previous study has investigated this type of business issue.

\footnotetext{
${ }^{6}$ A stock variable is measured at one specific time and represents a quantity existing at the specific point in time, which may have accumulated in the past.
} 


\section{Consumers' choices and behaviors}

Table 3 presents the take-up rates of BT offers for three groups of consumers, who are divided into the subgroups as explained in Sect. 3.2. The take-up rates of the offer with $\mathrm{PR}=0 \%$ are obviously higher than the rates of offers with $\mathrm{PR}>0 \%$. For example, in the baseline offer (Group A), the take-up rates of the first three contracts, having $0 \%$ in PR, are at least $2.34 \%$ (8.98\% in A3-6.64\% in A4) higher than the offers with $1.9 \%$ in PR. In the offer Group B, the take-up rate of 0\% PR contracts is at least 9.2\% (19.58\% in B4-10.38\% in B5) higher than the contracts with positive PR (i.e., 1.9\% in PR). In Group C, the takeup rate of offers with $0 \%$ in $P R$ is at least $6.88 \%$ higher than the ones of positive PR offers (i.e., 1.9\% in PR). For the three groups (A, B, and C), the take-up rates of two better offers in $B$ and $C$ are nearly triple the take-up rates of Group $A$ for good contracts with $0 \%$ in $P R$ and low FFL. Even for bad contracts with high interest rates (contracts A5-C5 and A6C6), the take-up rates are nearly double between $\mathrm{A}$ and $\mathrm{B}$ and $\mathrm{C}$.

\subsection{An illustrative model}

This study uses a model of contract choice and offer acceptance. Let $D$ denote a BT offer and $(\mathrm{X}, \varepsilon)$ denote the observed and unobserved customer characteristics. Each BT offer has parameters PR, FFL, PD, one-time maximum fee, respectively. In estimating such a model, a benefit of having a randomized dataset is that this study can treat the four contract variables as exogenous. Once customers accept the offer, they can choose between two options. Even though the contract offer $(D)$ is randomly assigned in the randomized sample, the customers' contract choices are not random; the choices can depend both on observed $(X, D)$ and on unobserved $(\varepsilon)$ variables where $\varepsilon$ stands for an error. This study defines a discrete choice model to explain the consumers' choice. ${ }^{7}$

Let $W$ denote consumers' choice, then

$$
W= \begin{cases}0 & \text { if } B=0 \text { (customer rejects BT offer) } \\ 1 & \text { if } B=1 \text { (customer accepts and chooses FFL contract) } \\ 2 & \text { if } B=2 \text { (customer accepts and chooses PR contract) } \\ 3 & \text { if } B=3 \text { (customer accepts and chooses both PR and FFL contracts) }\end{cases}
$$

Here, $B$ denotes an indicator that a customer rejects the offer $(B=0)$, or accepts the FFL offer $(B=1)$ or the PR offer $(B=2)$ or both of PR and FFL offers $(B=3)$. Then, corresponding probabilities of choosing different contracts are denoted: $P_{F}$ is the probability of choosing FFL not PR contract; $P_{P}$ is the probability of choosing PR not FFL contract; and $P_{F P}$ is the probability of choosing both. The probability of choosing neither is linearly dependent. Therefore, it does not provide any additional information.

This study uses the following multinomial choice model to determine what contract the customer chooses:

$$
\begin{aligned}
U_{0} & =0 \\
U_{F} & =X_{F} \beta_{F}+\varepsilon_{F} \\
U_{P} & =X_{P} \beta_{P}+\varepsilon_{P} \\
U_{F P} & =U_{F}+U_{P}+\Gamma,
\end{aligned}
$$


Table 4 Multinomial logit for consumers' choices

\begin{tabular}{|c|c|c|c|c|c|c|}
\hline \multirow[t]{2}{*}{ Variables } & \multicolumn{2}{|c|}{ Choose FFL offer } & \multicolumn{2}{|c|}{ Choose PR offer } & \multicolumn{2}{|c|}{ Choose both offers } \\
\hline & Coef. & SE & Coef. & SE & Coef. & SE \\
\hline FFL & $-70.7 e-02$ & $0.04^{* * *}$ & $-9.98 e-02$ & $0.03^{* * *}$ & $-5.27 e-02$ & $0.08^{* * *}$ \\
\hline$P R$ & $7.34 \mathrm{e}-02$ & $0.03^{*}$ & $-39.95 e-02$ & $0.02^{* * *}$ & $6.85 e-02$ & 0.07 \\
\hline PD & $-5.13 e-02$ & $0.01^{* * *}$ & $15.38 \mathrm{e}-02$ & $7.6 e-03^{* * *}$ & $0.83 e-02$ & 0.02 \\
\hline BT fee & $-0.85 e-02$ & $-7 e-04^{* * *}$ & $-1.38 \mathrm{e}-02$ & $5 e-04^{* * *}$ & $-1.22 \mathrm{e}-02$ & $1.5 \mathrm{e}-03^{* * *}$ \\
\hline PB balance & $-4.87 e-05$ & $-1.89 \mathrm{e}-05^{* * *}$ & $7.14 \mathrm{e}-05$ & $1.71 \mathrm{e}-05^{* * *}$ & $2.31 e-05$ & $4.06 \mathrm{e}-05$ \\
\hline Finance charge & 0.01 & $1.4 \mathrm{e}-03^{* * *}$ & $-3.9 e-03$ & $1.4 \mathrm{e}-03^{* * *}$ & 0.01 & $3.1 e-03^{* * *}$ \\
\hline Fee & $1.4 \mathrm{e}-03$ & $2.7 e-03^{* * *}$ & 0.03 & $2.1 \mathrm{e}-03^{* * *}$ & 0.01 & $4.6 e-03^{* * *}$ \\
\hline Spending & $6.62 e-06$ & $1 e-04$ & $-3 e-04$ & $6.58 \mathrm{e}-05^{* * *}$ & $2 e-04$ & $2 e-04$ \\
\hline Payment & $-2 e-04$ & $4.87 e-05^{*}$ & $4 e-04$ & $2.92 \mathrm{e}-05^{* * *}$ & $2.78 \mathrm{e}-05$ & $9.9 e-05$ \\
\hline Cash spend & $-9 e-04$ & $4 e-04^{* * *}$ & $-4 e-04$ & $2 e-04^{* * *}$ & $-6 e-04$ & $3 e-04^{*}$ \\
\hline CCC \# & -0.2 & $0.08^{* * *}$ & -0.1 & 0.07 & -0.15 & 0.18 \\
\hline EFX\# & $-1.48 \mathrm{e}-02$ & $4.2 e-03$ & $6.8 \mathrm{e}-03$ & $2.7 e-03^{* * *}$ & $-3.4 e-03$ & 0.01 \\
\hline EFX limit & $-1.25 e-07$ & $5.43 e-07$ & $4.17 e-07$ & $3.33 e-07$ & $-3.83 e-06$ & $1.71 e-06^{* * *}$ \\
\hline CCC limit & $-4.97 e-05$ & $7.24 \mathrm{e}-06$ & $1.92 \mathrm{e}-05$ & $5.09 e-06$ & $1.64 \mathrm{e}-05$ & $1.54 \mathrm{e}-06$ \\
\hline Behavior score & $-1 e-03$ & $2 e-04^{* * *}$ & $9 e-05$ & $1 e-04$ & $6 e-04$ & $4 e-04^{*}$ \\
\hline FICO score & $-5.89 e-03$ & $6 e-04^{* * *}$ & $-1.3 e-03$ & $4 e-04^{* * *}$ & $-6.3 e-03$ & $1.2 e-03^{* * *}$ \\
\hline CCC U. ratio & -0.23 & $0.09^{* * *}$ & -0.77 & $0.07^{* * *}$ & -1.29 & $0.21^{* * *}$ \\
\hline EFX U. ratio & $108.53 e-02$ & $0.15^{* * *}$ & $3.87 e-02$ & $0.13^{* * *}$ & 0.49 & 0.33 \\
\hline
\end{tabular}

All characteristics are averaged. CCC \# credit card numbers in RBS bank. EFX \# the total number of credit cards from Equifax data. CCC limit the credit card limit in RBS bank. EFX limit a total card limit in Equifax data. Behavior score is the credit score calculated by RBS bank, and FICO score is the credit score from Equifax bureau. $U$ utilization

From the table, consumers would like to reject the PR offers even when FFL increases. Therefore, FFL is a key parameter for consumers to make a choice of BT offer. Thus, FFL significantly impacts the consumers' choice most at $5 \%$ confidence. PR increase leads to less acceptance of PR offer and more acceptance of the FFL offer. In sum, consumers with good credit records take advantage of the PR offer. In contrast, constrained consumers choose the FFL offer in order to enjoy a low interest rate. Consumers who choose both offers have good credit records but also high finance charges

*, *** Coefficients are significant at the level of 10 and $5 \%$

where $\Gamma=\left(U_{F P}-U_{P}\right)-\left(U_{F}-U_{0}\right)$ which measures the extent as to which the added utility $(U)$ of accepting offer $F$ (FFL contract) increases if the offer $P$ (PR contract) is also accepted. This study assumes that $\Gamma$ is constant across all consumers. $\varepsilon_{F}$ and $\varepsilon_{P}$ are error terms that describe unobserved variations in utility. This study assumes the following error structure:

$$
\left(\begin{array}{l}
\varepsilon_{F} \\
\varepsilon_{P}
\end{array}\right)=N\left(0,\left[\begin{array}{ll}
1 & \sigma \\
\sigma & 1
\end{array}\right]\right)
$$

The observed data are expressed by $(B, W)$. Let $F(U)$ be the distribution function of $U=\left(U_{F}, U_{P}, U_{F P}\right)$ implied by the above assumption. Note that $F$ stands for a function, different from the subscript $(F)$ for FFL Hence, $B=i$ implies $\max \left(U_{0}, U_{F}, U_{P}, U_{F P}\right)=U_{i}$, for $i=0, F, P, F P$ choice probabilities will be given by:

$$
\begin{aligned}
P_{F} & =\int_{U} I\left(U_{F} \geq 0\right) I\left(U_{F} \geq U_{P}\right) I\left(U_{F} \geq U_{F P}\right) \mathrm{d} F(U), \\
P_{P} & =\int_{U} I\left(U_{P} \geq 0\right) I\left(U_{P} \geq U_{F}\right) I\left(U_{P} \geq U_{F P}\right) \mathrm{d} F(U) \text { and } \\
P_{F P} & =\int_{U} I\left(U_{F P} \geq 0\right) I\left(U_{F P} \geq U_{F}\right) I\left(U_{F P} \geq U_{P}\right) \mathrm{d} F(U) .
\end{aligned}
$$




\subsection{Estimation results}

Table 4 summarizes the parameter estimates of consumers' choices. Besides the column of variables, the first two columns report estimation results for consumers who choose the FFL offer. For customers choosing the FFL offer, the FFL, PD, and maximum BT fee are negative on their choices, while PR is positive on their choices. The $1 \%$ increase in FFL significantly decreases the probability of choice by $70.7 \%$ and the increased $\$ 1$ in BT fee decreases the probability by $0.85 \%$. If PR increases by $1 \%$, the FFL offer appears to be more competitive, and more consumers choose the FFL by $7.34 \%$. The longer PD is better along with the PR offer since the FFL is not related to the PD. Hence, a 1-month shorter duration leads $5.13 \%$ more consumers to choose the FFL offer.

The third and fourth columns report estimation results regarding consumers who choose the PR offer. The key parameter is obviously the PR, which has the probability of choosing the offer up to $39.95 \%$ if it decreases by $1 \%$, and 1 -month extension of PD increases the probability of choosing the offer by $15.38 \%$. The BT fee is also negative on the choice of PR offer, as well. The interesting finding here is that along with the $1 \%$ increase in FFL, the probability of choosing PR offer decreases by $9.98 \%$. This may be explained as a bad offer has a signal with higher FFL. Furthermore, many consumers who choose PR are not budget constrained. Therefore, they do not eager to borrow money from credit card companies. They are waiting for good offers to enjoy the best benefit.

The last two columns report estimation results for consumers who choose both offers. Only FFL and BT fee of contract parameters have a significant impact on consumers' choice. About half of consumers decline the choice of both offers with $1 \%$ increase in FFL. Therefore, this study considers that the FFL mostly influences the choice among all four contract parameters.

Hereafter, this study is interested in examining which category of consumers chooses different types of offers. The constrained budget is a major factor that has an impact on consumers' choices. The constrained consumers in the RBS bank decrease by $23 \%$ probability to accept FFL offer and decrease by $77 \%$ to accept PR offer if corresponding FFL and PR increase by $1 \%$. See the second row on CCC U. ratio from the bottom of Table 4. If consumers have their total budget limits, the probability of choosing the FFL offer increases significantly to $108.5 \%$, but to just the $3.87 \%$ probability of choosing the PR offer. Hence, consumers with serious budget limits likely avoid the limit of PD and borrow more through FFL offer. See the last row on EFX U. ratio of Table 4.

There are three different effects to FFL offer and the PR offer. First, consumers carrying more high interest balance prefer to accept the PR offer even with an increased PR, but the probability of choosing the FFL offer declines. Second, the total number of credit cards holds by consumer gives an impact on the choice in an opposite manner. The more cards the consumers have, the lower the probability of choosing the FFL offer. However, the probability of choosing the PR offer increases if consumers have more cards. This result is consistent with the card limits and the consumers' credit records. Usually, consumers with good credit records have more cards with higher credit limits because credit card companies send them credit card offers based on their credit records. Therefore, consumers with good credit records tend to choose PR offers to take full advantage of BT offers. Finally, our finding is confirmed by a finance charge. Consumers who need 
to pay a higher finance charge prefer the FFL offer but decrease probability of choosing the PR offer. Overall, consumers with good credit records take advantage of the PR offer. In contrast, constrained consumers choose the FFL offer in order to enjoy the low interest rate comparing to regular purchase rate. Consumers who choose both offers have good credit records but also high finance charges.

\section{Empirical specification}

As an extension of the previous investigation in Sects. 3 and 4, this section is interested in examining how the short-term finance of consumers is impacted by the BT offers in terms of $\Delta$ Debt, purchase spending, and payment, where $\Delta$ Debt stands for a change on debt. This study restricts the proposed analysis on only experienced consumers so that it can find how finance situations are changed by a change of parameters (i.e., PR, FFL, PD, and fee). The important parameters are FFL and PR. Consumers use these parameters to decide which option should use to pay off their debts. As discussed in Sect. 3, the other two parameters do not have any significant impact on the consumer choice.

Controlling for PD, this study has three contract parameters that need to be considered. Specifically, this study estimates the model that has the following structure:

$$
Y_{i t}=\alpha+\beta_{0} R_{i t}+\beta_{1} X_{i}+\varepsilon_{i t}
$$

where the outcome variable $Y_{i t}$ represents either the payments $P_{i t}$ or spending $S_{i t}$ in account $i$ in month $t$ or a change on the amount of debt $\left(\Delta \mathrm{Debt}_{i t}\right)$, including a change of CCC balance $\left(\triangle C C C_{i t}\right)$, a change of the EFX balance $\left(\triangle \mathrm{EFX}_{i t}\right)$, and a change of PB balance $\left(\Delta \mathrm{PB}_{i t}\right)$ at the end of month $t$. Here, $\Delta$ stands for a change. $R_{i t}$ represents contract parameters including PR, FFL, and maximized fee. $X_{i}$ stands for average historical consumer characteristics before campaign, which consists of payments, purchase spending, cash advance, finance charge, fee, the total number of specific bank credit cards, the total number of all open bank credit cards, the behavior score from a specific bank, the FICO score from Equifax bureau, the credit limit of specific bank credit cards, the total credit limit of all bank credit cards, the protected balance, the utilization ratio of specific bank credit cards, and the utilization ratio of all credit cards. All of such characteristics are averaged over 6 months of historical data before the campaign. Additionally, the outcome variable estimates are measured on average.

The coefficient $\beta_{0}$ in Eq. (1) measures the response of an outcome variable in terms of dollars to the offer receipt. The summation of parameters $\left(\sum_{t=0}^{8} \beta_{0}\right)$ represents the sum of amounts in the outcome variables changed during $t$ months so that it indicates the total effect of the outcome variable after 8 months. Thus, this study can examine the total and monthly effects of every month after campaign for $t$ months for $t=1,2$, ..., 8 and then examines what occurs under an increase in the rate of PR or FFL by $1 \%$. Because of a large dataset utilized in this study, being linked with Equifax Bureau, this study can examine $\triangle \mathrm{EFX}$ balance, indicating the aggregate debt of consumers in credit bureau. Thus, it is possible to examine whether the response of all credit card balances reinforces or offsets the response of balances on examined credit card accounts.

Based upon the above description, this study estimates the average effect of five outcome variables to the BT offer in terms of total and monthly effects. Table 6, along with Table 5, describes such total effect and reports the coefficients which summarize 
Table 5 Regression results on take-up rates

\begin{tabular}{|c|c|c|c|c|c|c|}
\hline \multirow[t]{3}{*}{ Variables } & \multirow{2}{*}{\multicolumn{2}{|c|}{$\begin{array}{l}\text { Take-up rate } \\
\text { Group }(A): P D=6, \text { fee }>0\end{array}$}} & \multirow{2}{*}{\multicolumn{2}{|c|}{$\begin{array}{l}\text { Take-up rate } \\
\text { Group (B): PD = } 12\end{array}$}} & \multirow{2}{*}{\multicolumn{2}{|c|}{$\begin{array}{l}\text { Take-up rate } \\
\text { Group }(C): P D=6, \text { fee }=0\end{array}$}} \\
\hline & & & & & & \\
\hline & Coef. & SE & Coef. & SE & Coef. & SE \\
\hline FFL & $-1.06 e-02$ & $3.53 \mathrm{e}-03^{* * *}$ & $-5.71 e-02$ & $0.01^{* * *}$ & $-4.01 e-02$ & $4.77 e-03^{* * *}$ \\
\hline$P R$ & $-1.54 \mathrm{e}-02$ & $1.91 \mathrm{e} 03^{* * *}$ & $-2.45 e-02$ & $0.01 * * *$ & $-2.42 e-02$ & $3.53 e-03^{* * *}$ \\
\hline BT fee & $-3.29 e-04$ & $2.41 e-04$ & $-7.75 e-04$ & $4.3 e-04^{*}$ & Omitted & \\
\hline PB balance & $1.18 \mathrm{e}-06$ & $1.66 \mathrm{e}-06$ & $1.57 e-06$ & $3.82 \mathrm{e}-06$ & $4.28 \mathrm{e}-06$ & $2.81 e-06$ \\
\hline Finance charge & $4.87 e-04$ & $1.33 \mathrm{e}-04^{* * *}$ & $-1.86 e-04$ & $3.06 e-04$ & $3.34 \mathrm{e}-04$ & $2.22 \mathrm{e}-04$ \\
\hline Fee & $-5.18 e-04$ & $1.78 \mathrm{e}-04^{* * *}$ & $-2.79 e-03$ & $4.17 \mathrm{e}-04^{* * *}$ & $-3.71 e-03$ & $3.01 e-04^{* * *}$ \\
\hline Spending & $-1.38 \mathrm{e}-05$ & $7.82 \mathrm{e}-06^{*}$ & $-2.61 e-05$ & $1.52 \mathrm{e}-05^{*}$ & $-1.69 e-05$ & $1.22 \mathrm{e}-05$ \\
\hline Payment & $1.05 e-05$ & $3.19 \mathrm{e}-06^{* * *}$ & $2.63 e-05$ & $7.27 e-06^{* * *}$ & $1.8 \mathrm{e}-05$ & $5.33 e-06^{* * *}$ \\
\hline Cash spend & $3.88 \mathrm{e}-05$ & $3.57 e-04$ & $2.69 \mathrm{e}-04$ & $8.63 e-05^{* * *}$ & $1.06 \mathrm{e}-04$ & $4.42 \mathrm{e}-05^{* * *}$ \\
\hline CCC\# & $4.28 \mathrm{e}-05$ & $6.45 e-03$ & $-6.67 e-03$ & 0.01 & $3.23 e-03$ & 0.01 \\
\hline EFX\# & $-6.33 e-04$ & $2.87 e-04^{* * *}$ & $3.73 e-04$ & $6.39 \mathrm{e}-04$ & $1.37 e-03$ & $4.7 e-04^{* * *}$ \\
\hline EFX limit & $-1.02 \mathrm{e}-07$ & $3.58 \mathrm{e}-08^{* * *}$ & $9.04 \mathrm{e}-08$ & $8.31 e-08$ & $1.12 \mathrm{e}-07$ & $6.07 e-08^{*}$ \\
\hline CCC limit & $-1.57 e-06$ & $5.20 \mathrm{e}-07^{* * *}$ & $-4.07 e-08$ & $1.15 \mathrm{e}-06$ & $-2.67 e-06$ & $8.67 \mathrm{e}-07^{* * *}$ \\
\hline Behavior score & $4.67 e-05$ & $1.48 \mathrm{e}-05^{* * *}$ & $-7.22 \mathrm{e}-05$ & $3.12 \mathrm{e}-05^{*}$ & $-2 e-05$ & $2.43 e-05$ \\
\hline FICO score & $-2.49 e-04$ & $4.56 \mathrm{e}-05^{* * *}$ & $-2.98 e-04$ & $1.02 \mathrm{e}-04^{* * *}$ & $-1.5 e-04$ & $7.54 \mathrm{e}-05^{* * *}$ \\
\hline CCC U. ratio & -0.04 & $6.73 \mathrm{e}-03^{* * *}$ & -0.07 & $0.02^{* * *}$ & -0.10 & $0.01^{* * *}$ \\
\hline EFX U. ratio & 0.06 & $0.13^{* * *}$ & 0.10 & $0.03^{* * *}$ & 0.09 & $0.02^{* * *}$ \\
\hline Cons & 0.41 & $0.05^{* * *}$ & 0.76 & $0.10^{* * *}$ & 0.54 & $0.07^{* * *}$ \\
\hline
\end{tabular}

All characteristics are averaged. U ratio utilization ratio, EFX \# the total number of credit cards from Equifax data. CCC limit a credit card limit in RBS bank. EFX limit a total card limit in Equifax data. U ratio utilization ratio

The behavior score is a credit score calculated by RBS bank, and the FICO score is a credit score from Equifax bureau. The coefficients of FFL and PR for take-up rate are significantly negative, as expected. The decreasing magnitudes are stronger than it for all consumers, especially for FFL, and they are severe for the two better offer groups ( $B$ and $C$ )

${ }^{*},{ }^{* * *}$ Coefficients are significant at the level of 10 and $5 \%$

the total effect of 8 months of the BT offer. The monthly effect is estimated and shown in a more straightforward manner. Figures 3,4 , and 5 reflect coefficients $\left[\beta_{0}\right.$ in Eq. (1)] along with the $95 \%$ confident intervals. The three figures exhibit how the monthly effect of every dependent variable changes and which change is important in predicting the consumer's behavior to the BT offer in different months. Usually, consumers make their decisions according to the duration of BT offers if they are rational. Therefore, their decisions can be measured through their behaviors. For example, consumers pay off all debts before the end of the offer, and they may take advantage of the offer to pay other debt with higher interest rate, which can be confirmed by checking their payment behaviors.

\section{Regression results}

This research first applies Eq. (1) to measure take-up rates of the three groups whose results are summarized in Table 5. The coefficients of FFL and PR for take-up rate are significantly negative. Furthermore, the negative effects of FFL and PR are stronger to consumers for two better offers. The take-up rates decrease $1.06 \%$ with an increase in FFL and $1.54 \%$ with an increase in PR in the baseline group (A). See the second column of Table 5. The rates decrease $5.71 \%$ for FFL and $2.45 \%$ for PR in the second group (B). These rates decline to $4.01 \%$ for FFL and $2.42 \%$ for PR in the third group (C). The 


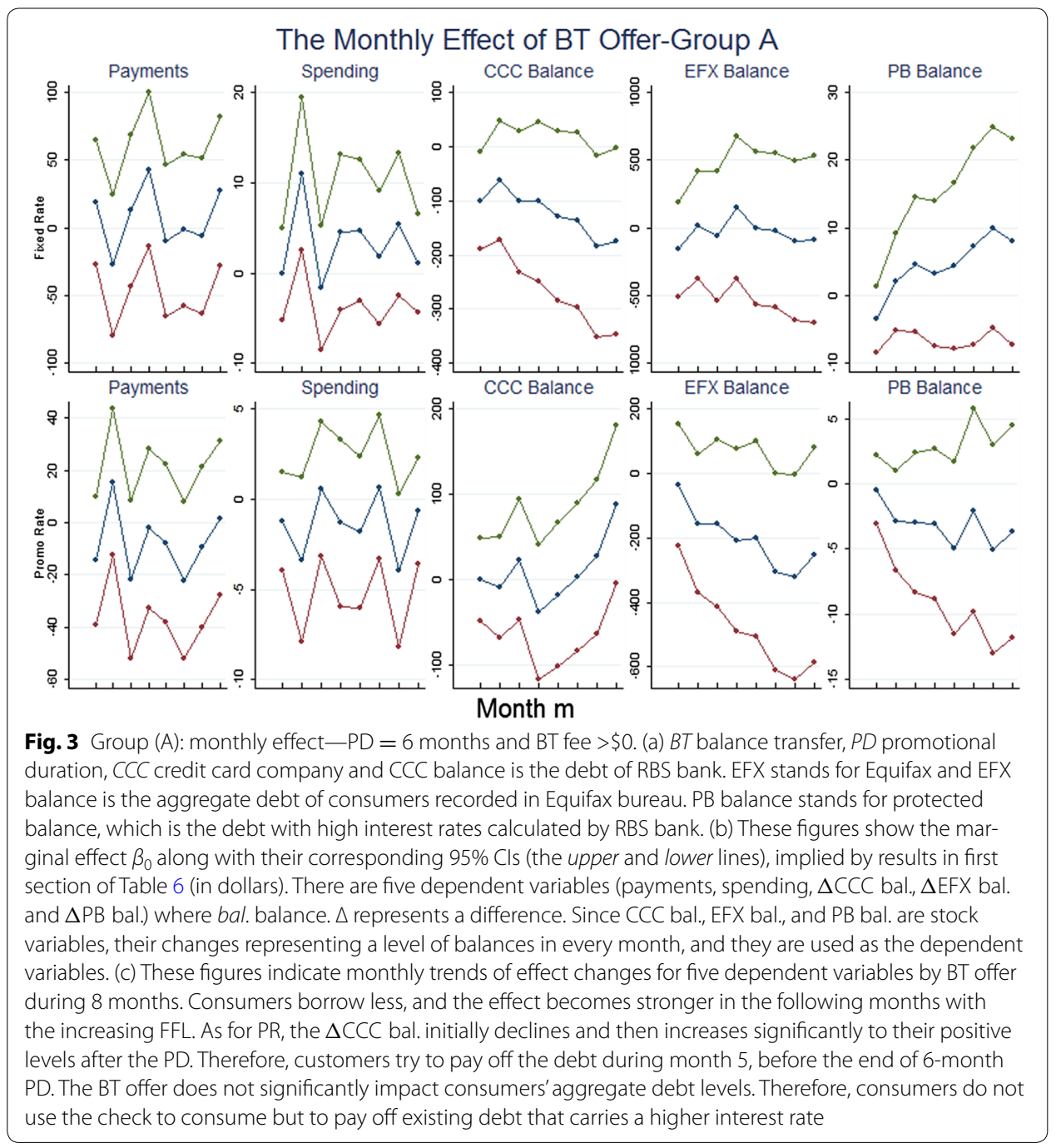

decreasing magnitudes are larger than the ones for all consumers, especially for FFL in the level that they are higher for the two better offer groups. As the interest rate increases, the take-up rate declines, as found in Table 3. Although the effect of PR doubles in better offer groups, it still impacts on the choice less than FFL.

\subsection{Result regarding baseline offer (A)}

The first section of Table 6 and Fig. 3 presents the estimation results for the baseline group (A). In Table 6 , the higher the FFL, the lower the $\Delta$ Debt. The coefficients of payments and spending are positive. The total payment increases by $\sum_{t=0}^{8} \beta_{0}=\$ 88.79$ on average (significant at the $10 \%$ level). See the row on FFL in the column on total payment of Table 6 . However, the $\sum_{t=0}^{8} \beta_{0}$ on the spending is not significant as found in the column on total spending of Table 6. The most significant result on which is $\triangle \mathrm{CCC}$ balance, it significantly decreases by $\$ 145.9$ on average in eight months following the campaign. See the column on the row on FFL in the column of $\triangle \mathrm{CCC}$ balance in Table 6. $\triangle \mathrm{EFX}$ and $\Delta \mathrm{PB}$ balances decline by $\$ 130.28$ and $\$ 15.03$, respectively, as found in the last two columns. The signs are not significant. 


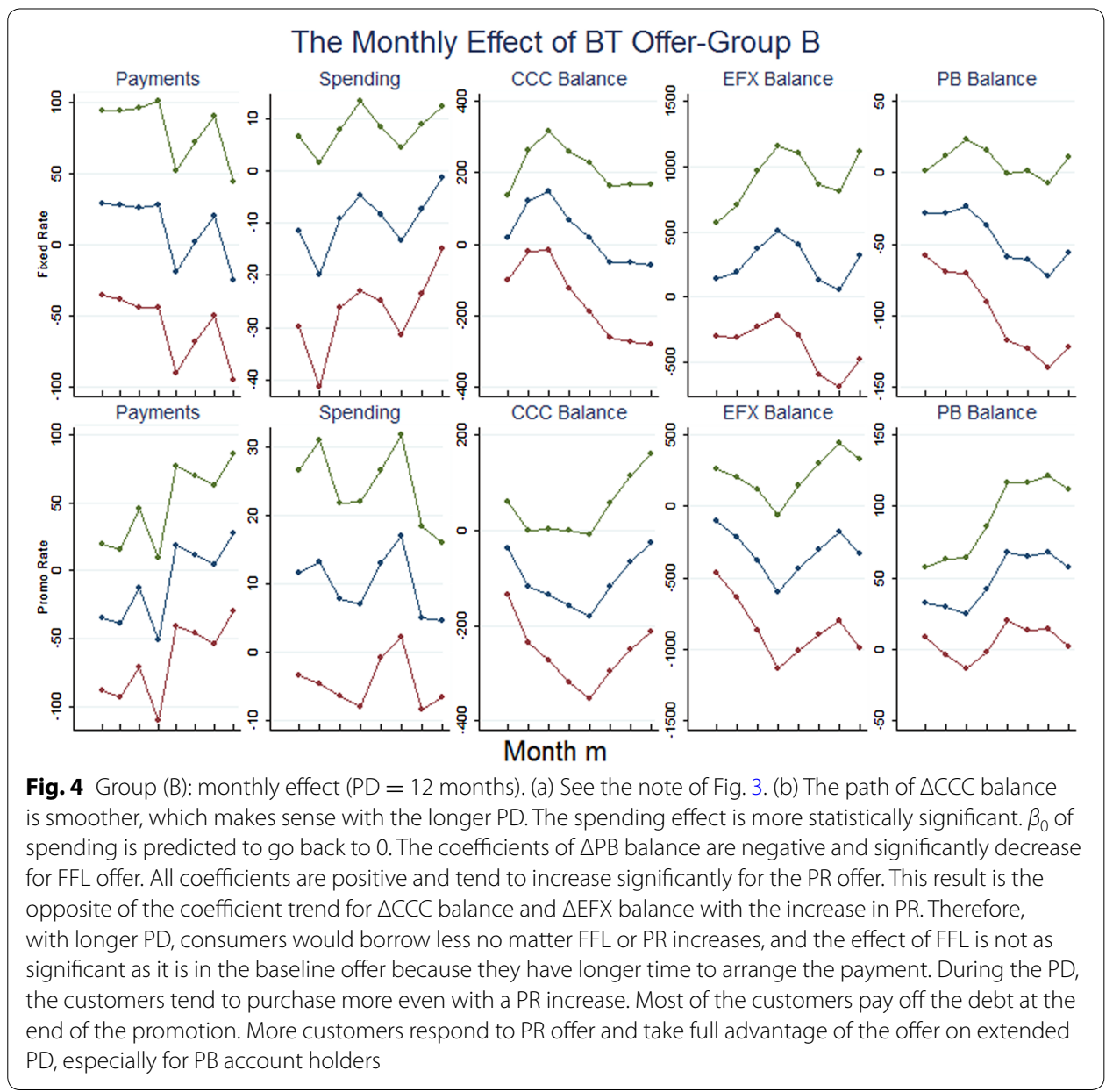

Actually, at the same time the higher the PR is, the higher the $\Delta$ Debt. Outcome variables (payments and spending) have negative coefficients. The $\triangle \mathrm{CCC}$ balance improves by $\sum_{t=0}^{8} \beta_{0}=\$ 87.61$ (significant at the $5 \%$ level) on average, as found in the row on PR in the column on $\triangle \mathrm{CCC}$ balance in Table 6 . The total payment decreases by $\$ 45.33$ on average (significant at the $10 \%$ level). The sign for the other two balances is the same (i.e., negative) as the $\triangle C C C$ balance and their magnitudes increase by $\$ 60.29$ and $\$ 3.55$, but they are not statistically significant, as found in the last two columns of Table 6. However, they are economically significant because the signs reflect the average change of short-term finance per credit card account. The total purchase spending is still not significant as found in the row on PR in the column on total spending. The results indicate that the effects of a one-time maximized BT fee are all not significant.

The monthly baseline results are reflected by the coefficients of five outcome variables in Fig. 3. See the middle line in every graph. The upper and lower lines represent 95\% confidence intervals. Starting with the payment graph, from the first to the eighth month, the monthly payment fluctuates between -5 and 25 with a $1 \%$ increase in FFL, and most of them are positive but not significant. Along with the $1 \%$ increase in PR, the monthly payment fluctuates between -15 and 5 , and most of them are nonsignificantly negative. Therefore, the campaign by BT offers does not have a large impact on 


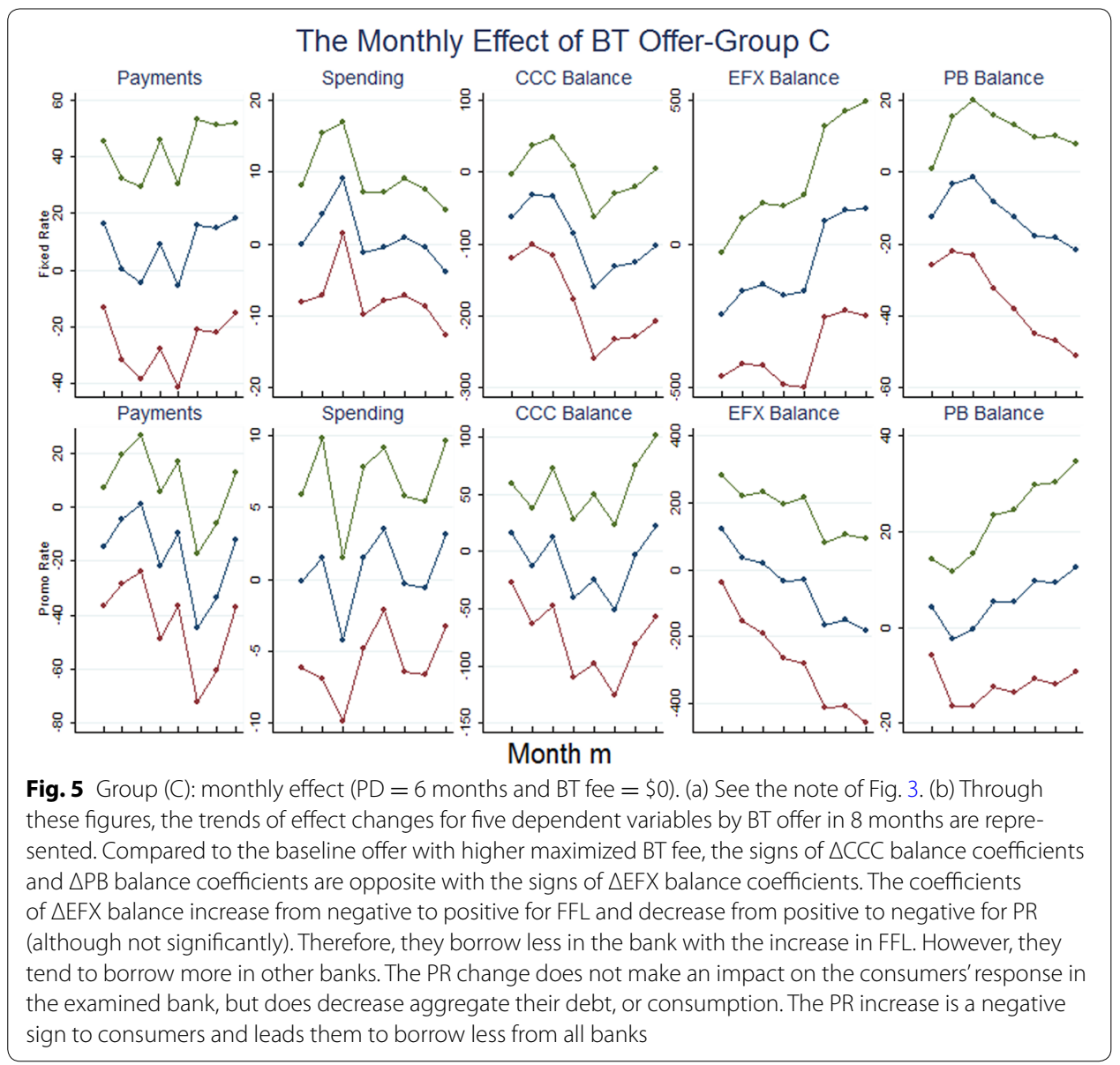

the monthly payment. It is increasing from negative to positive starting from month 6 for PR. This confirms the payoff behavior of customers for PR.

As for purchase spending, most monthly spending is not significant along with an increase in FFL, except in the third month. The consumer decreases spending by about $\$ 10$. The other monthly purchases show a small declining trend. The path for PR is similar to FFL. Most of the $\beta_{0}$ s of 8 months are not significant, and the amounts are close to 0 . The difference is that most of the $\beta_{0} \mathrm{~s}$ are above 0 with the increase in FFL, but most $\beta_{0} \mathrm{~s}$ are below 0 with an increase in PR. The signs on the coefficients for the PR and FFL are opposite.

Along with the increase in FFL, the $\triangle \mathrm{CCC}$ balance is negative and continues to decrease significantly after the offer campaign. Consumers borrow less money from the banks examined in this study. However, the decreasing coefficient trend tends to be stable in the last 2 months. As for PR, the $\triangle \mathrm{CCC}$ balance is negative in the first 6 months and is positive after the first 6 months. It initially declines and then increases significantly to a positive level after the PD. Customers try to pay off the debt during month 5, before the end of 6-month PD.

As for $\triangle \mathrm{EFX}$ balance, the path is flatter than the path for payments. The $\triangle \mathrm{EFX}$ balance varies around 0 with the increase in FFL. This result indicates that increasing FFL 


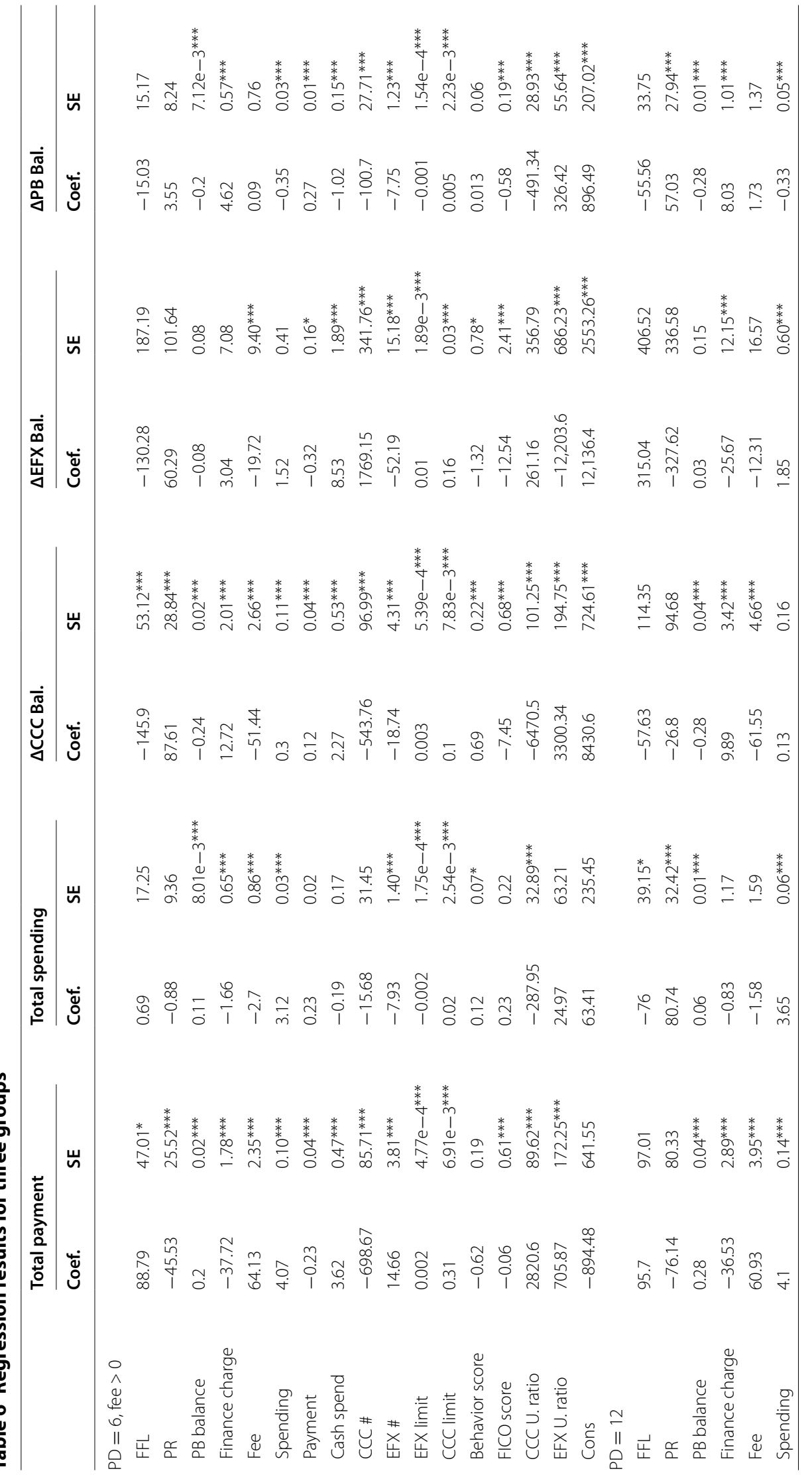




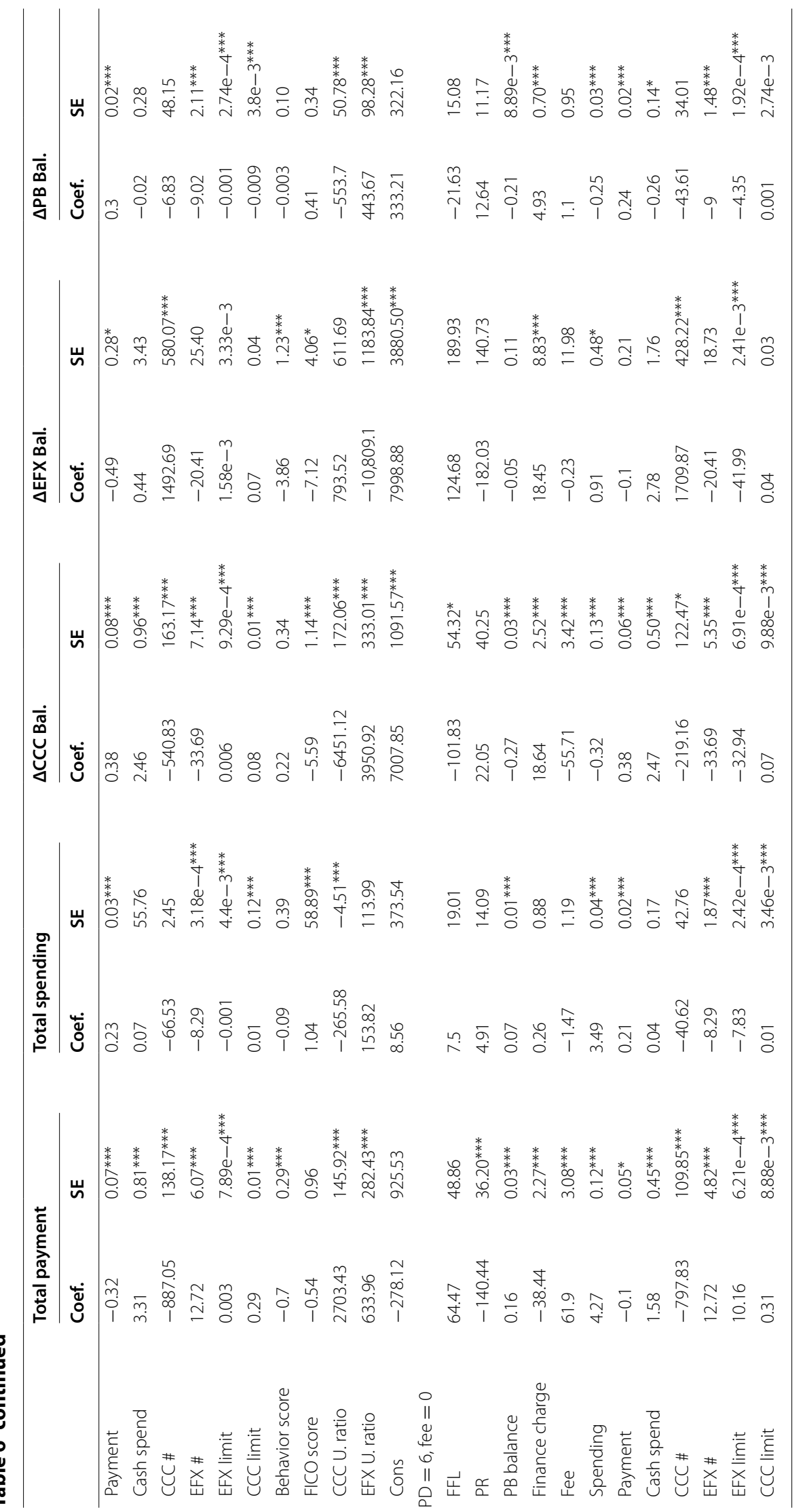




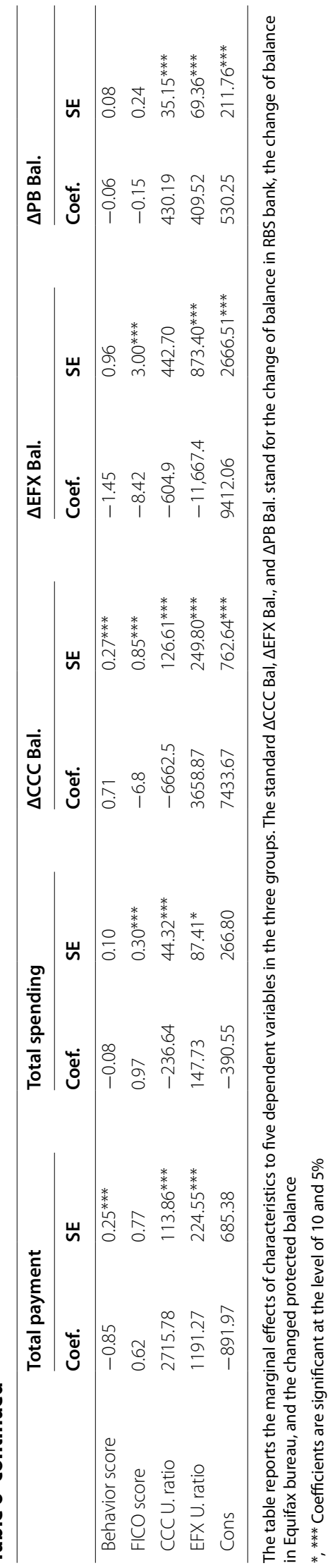


in the examined banks will not make an impact on the aggregate debt level of customers. Along with the increase in PR, the $\triangle \mathrm{EFX}$ balance first slightly decreases and increases to a positive level in the third month. Then, it declines sharply through the sixth month and rebounds to the amount 0 . This implies that customers pay off debt at the end of PD. Later, the aggregate debt level goes return to its original level.

The path for the $\triangle \mathrm{PB}$ balance starts from a negative number and increases in the following months with the increase in FFL. For the PR, $\beta_{0}$ s decline in first 4 months and then they recover back to 0 at the end of the sixth month. The PB balance account holders carry balances with high interest rates. In other words, they borrow a lot from the bank, and the bank earns a lot of interest revenue from PB account holders. They try to make a good use of the promotion, but it will not make a major impact on them.

Summary The BT offer impacts on consumers' short-term finance significantly in the banks. The most interesting finding is that consumers change their internal debt levels oppositely to an increase in FFL and PR. Consumers tend to borrow less with an increase in FFL, which satisfies the hypothesis of LCH/PIH, but borrow more even with an increase in the PR, which rejects the hypothesis because it expects a lower borrowing if interest rate is increased. The take-up rate may explain this rejection of the hypothesis for PR because the take-up rate decreases if the PR increases. Therefore, the consumers who still borrow more from the banks when PR increases are budget constraint or they have other debt with much higher interest rates. The BT offer does not significantly impact consumers' aggregate debt levels. However, consumers are inclined to borrow less if FFL or PR increases. Therefore, consumers do not use the check for their consumptions but to pay off existing debt that carries a higher interest rate. But spending using the credit card is not significant. Since only spending in examined bank is available and an amount of total spending is not available to us from our data, the effect of offer to total spending can be confirmed from EFX balance. Although the monthly payment effect is not significant, the total effect implies that consumers pay more with an increased FFL, but pay less with an increased PR.

\subsection{Result regarding 12-month promotion duration offer (B)}

The 12-month offer is a better offer (B) with a longer duration than the baseline offer (A). Section 2 of Table 6 and Fig. 4 presents the point estimation of total and monthly effects on BT. The total spending is significantly declining by $\$ 76$ on average with an increase in FFL and is significantly improving by $\$ 80.74$ on average with an increase in $\mathrm{PR}$. The effect is similar to that of $\triangle \mathrm{PB}$ balance. That is, the $\triangle \mathrm{PB}$ balance decreases by $\$ 55.56$ for FFL and increases by $\$ 57.03$ for PR. The smaller amount between $\Delta \mathrm{PB}$ balance and spending should be the payment of consumers back to the examined bank. The effects of payments, $\triangle \mathrm{CCC}$ balance, and $\triangle \mathrm{EFX}$ balance are not significant, as summarized in Table 6.

Paying attention to the response to the BT offer with 12-month PD, this study observes the almost same effect as found in the baseline offer (A) except the following aspects. First of all, the path of $\triangle \mathrm{CCC}$ balance is smoother because the coefficient is gradually increasing or decreasing and the change between every 2 months is similar. It is consistent with the longer PD, because consumers have longer time to arrange their payment than A. However, the effect of FFL is not as significant as it is in the baseline offer even 
though the trend is still decreasing. The coefficients of $\triangle \mathrm{CCC}$ balance are all negative for the PR offer. Second, a good change is that the spending effect is more statistically significant than the baseline offer. Along with an increase in FFL, all of the coefficients are negative. On the whole, $\beta_{0}$ is increasing with two troughs in the second and sixth months. With PR, the effect is opposite. $\beta_{0}$ is positive and shows a decreasing trend with one peak point in the sixth month. Although the end of promotion is not included in the figure, the declining trend may predict the coefficient back to 0 . Finally, the coefficients of $\triangle \mathrm{PB}$ balance are negative and significantly decrease for FFL offer. All coefficients are positive and tend to increase significantly for the PR offer. This result is the opposite of the coefficient trend for $\triangle \mathrm{CCC}$ balance and $\triangle \mathrm{EFX}$ balance with the increase in PR. This is different from the baseline offer on the baseline offer (A). Since PB account holders borrow a lot from the bank, the result indicates that they borrow more and more from the study bank after the PR offer receipt.

Summary Along with longer PD, consumers tend to borrow less no matter how FFL or PR increases. The effect of FFL is not as significant as it is in the baseline offer because they have longer time to arrange the payment. During the PD, customers tend to purchase more even with its PR increase. Most of the customers pay off the debt at the end of the promotion. More customers respond to PR offer and take full advantage of the offer on extended PD, especially for PB account holders.

\subsection{Result regarding 6-month promotion duration offer and BT fee $=\mathbf{0}$ (C)}

This type of offer $(C)$ is attractive to consumers than the baseline offer (A) because there is no maximized BT fee. The third section of Table 6 and Fig. 5 describes the result of total and monthly effects in terms of the coefficients. The total payment significantly declines with an increase in PR, but the total payment effect to FFL and the total spending effect are not significant in this offer. The only significant effect for $\triangle \mathrm{Debt}$ is $\triangle \mathrm{CCC}$ balance for FFL. It declines $\$ 101.83$ if FFL increases by 1 percent. This indicates that most of the consumers borrow less if interest rates are higher regardless of FFL or PR offers. The interesting result here is that the signs of $\triangle \mathrm{CCC}$ balance coefficients and $\triangle \mathrm{PB}$ balance coefficients are opposite with the signs of $\triangle \mathrm{EFX}$ balance coefficients, which tells that consumers will borrow more money from other banks if interest rates of offer in examined bank are increased.

There is no significant effect in spending and payment, which is similar to baseline offer (A). Compared to the baseline offer with higher maximized BT fee, the path of $\triangle C C C$ balance fluctuates more. Along with the increased FFL, the coefficients of the $\triangle \mathrm{CCC}$ balance decrease in the first 5 months and then begin increasing to the eighth month. The corresponding coefficient path of $\triangle \mathrm{CCC}$ balance for PR is not significant and fluctuates with a slight decreasing trend. The coefficient paths of $\triangle \mathrm{EFX}$ balance and $\triangle \mathrm{PB}$ balance are smoothly changed. The coefficients of $\triangle \mathrm{EFX}$ balance increase from negative to positive for FFL and decrease from positive to negative for PR (although not significantly). The coefficient paths for $\triangle \mathrm{EFX}$ balance are different from the ones of the baseline offer (A). $\triangle \mathrm{PB}$ balance coefficients decrease for FFL and increase for PR, which are consistent with the baseline offer and exhibit a similar trend to the $\triangle \mathrm{CCC}$ balance. The large difference between this offer $(\mathrm{C})$ and the baseline offer (A) comes from $\triangle \mathrm{EFX}$ balance. 
Summary When consumers obtain better offer without one-time maximized BT fee, they borrow less in the bank with an increase in FFL. However, they tend to borrow more in other banks. The PR change does not make an impact on the consumers' response in the examined bank, but does decrease aggregate their debt, or consumption. The PR increase is a negative sign to consumers and leads them to borrow less from all banks.

\section{Financial implications}

Recently, there are two ways for credit card companies to stimulate consumer borrowing: a BT offer and a cash-back offer. An important issue is which one is more efficient to motivate consumers and change their short-term finance. To discuss the issue, Agarwal et al. (2007) examined how consumers responded to the 2001 federal income tax rebates by using credit card data from one major issuer. The study belongs to a similar research group. They gave a $\$ 500$ rebate on average to existing customers. Although the dataset used for this study is different from their work, it is possible for us to examine whether

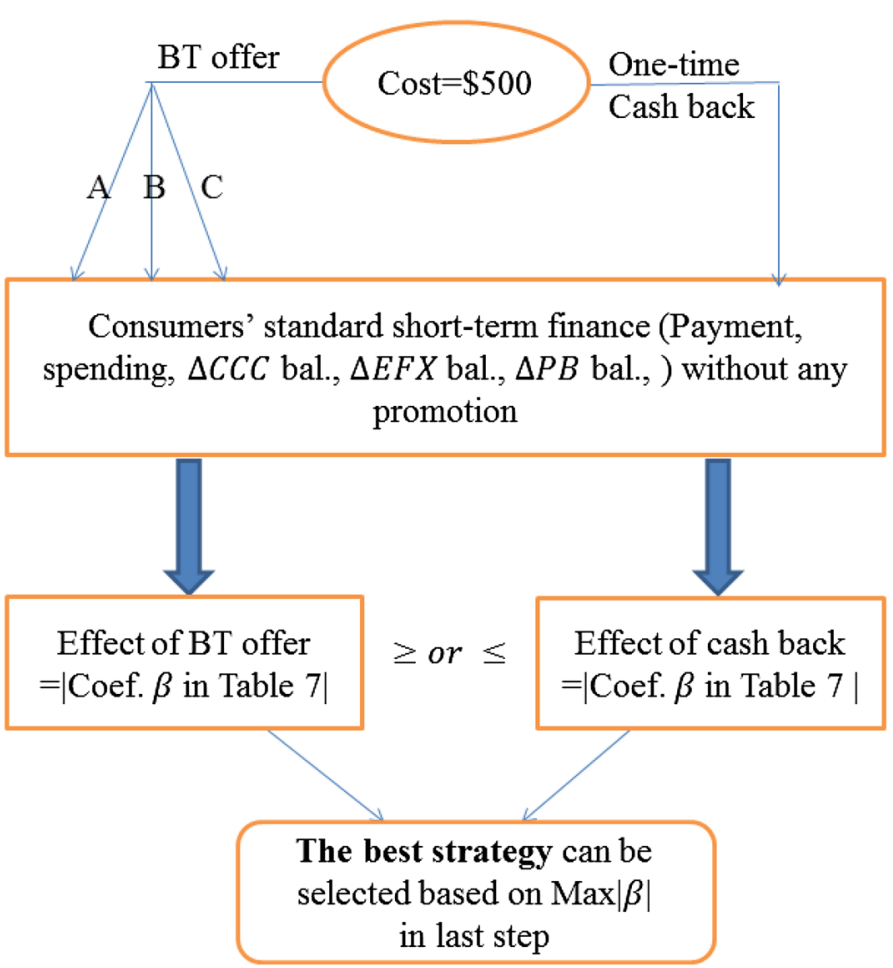

Fig. 6 Strategic implication. (a) $\triangle C C C$ bal. represents the difference of credit card company balance from RBS bank. $\triangle E F X$ bal. represents the difference of Equifax balance from Equifax bureau. $\triangle P B$ bal. represents the difference of protected balance calculated by RBS bank. (b) These three changes of debt are used as dependent variables because the balances are stock variables. Consumers'standard short-term finance situation which are summarized through five dependent variables payment, spending, $\triangle C C C$ bal., $\triangle E F X$ bal., $\triangle \mathrm{PB}$ bal. is obtained by counterfactual analysis. (c) Compared with the standard finance control, $\$ 500$ is applied to every account by two ways-BT offer or one-time cash back. There are three types of BT offer which are summarized in Table 1 as $a, b, c$. ( $a \mathrm{PD}=6$ months and fee $>\$ 0 . b P D=12$ months. $c$ PD $=6$ months and fee $=\$ 0$.). Using counterfactual analysis, how much consumers' short-term finance can be impacted are estimated for two ways. After comparing the effects of BT offer and cash back through absolute value of coefficients, the best strategy between BT offer and cash-back offer can be achieved by the maximum one 
the cash-back or the BT offer is better from a financial perspective. That will be the final task of this study.

Figure 6 summarizes the process of its financial implication. To compare the effect of payment, spending, and $\Delta$ Debt with the cumulative effect from the work of Agarwal et al. (2007), the total cost of each offer should be controlled at the same level for credit card companies. This study calculates the total cost of every offer group by considering that the cost of a bank is the London Interbank Offered Rate (LIBOR). LIBOR rate is the average of interest rated estimated by each of the leading banks in London that it would be charged were it to borrow from other banks. It is the primary benchmark for shortterm interest rates around the world. The cost is the average interest rate estimated by leading banks in London that they would be charged if borrowing from other banks. The average LIBOR rate from 2005 to 2006 was around 5\%. Then, this study defines the cost in every month as:

$$
\operatorname{cost}_{t}=\frac{(5 \%-\mathrm{PR}) \times \text { promobal }}{12}+\frac{(5 \%-\mathrm{FFL}) \times \text { fixbal }}{12},
$$

where $\operatorname{cost}_{t}$ is the cost for every month $t$. Promobal and fixbal stand for the BT amount of the consumers by using PR check and FFL check separately. Therefore, the total cost of the RBS bank is:

$$
\text { total cost }=\sum_{t=7}^{14} \operatorname{cost}_{t}
$$

After calculation, the total cost is $\$ 155.43$ for BT offer in Group A, $\$ 859.24$ for BT offer in Group B, and \$346.75 for BT offer in Group C. Because the cost of cash-back offer is $\$ 500$, above three total costs are adjusted to $\$ 500$, and the corresponding effect is summarized in Table 7.

To measure the effect, this study conducts a counterfactual analysis to measure a standard level of payment, spending and $\Delta$ Debt consumers make on average without taking up any promotion. According to the definition of cost $_{t}$ above, this research sets FFL and PR equal to $5 \%$, which infers to $\$ 0$ as the total cost. The zero total cost describes a scenario in which a credit card company does not give out any promotion regardless of BT offer and cash-back offer. Then, this study considers the counterfactual outcome variables as the standard and compares two effects from the BT offer and cash-back offers.

Table 7 summ arizes the comparison results on BT and cash-back offers at $\$ 500$ cost. The summary is that the magnitude of $\Delta \mathrm{Debt}$ from the BT offer is much larger than the $\Delta$ Debt from the cash-back offer. Because the $\triangle \mathrm{PB}$ balance is one special debt, which is calculated by the examined bank for a group of consumers, so that this study mainly focuses on the other two debts. The cash-back offer increases $\$ 27.5$ on average. In the baseline group (A), the total cost is just $\$ 155$. After adjusting the total cost to $\$ 500$, all effects of outcome variables should be amplified by more than three times, and then, the BT offer brings up at least $\$ 180 \Delta$ Debt, which is six times of $\$ 27.5$ of cash-back offer. After amplifying cost by three times, the payment effect is two times larger than the effect from cash back-\$48.7. However, the effect of spending is much smaller than their finding from cash 


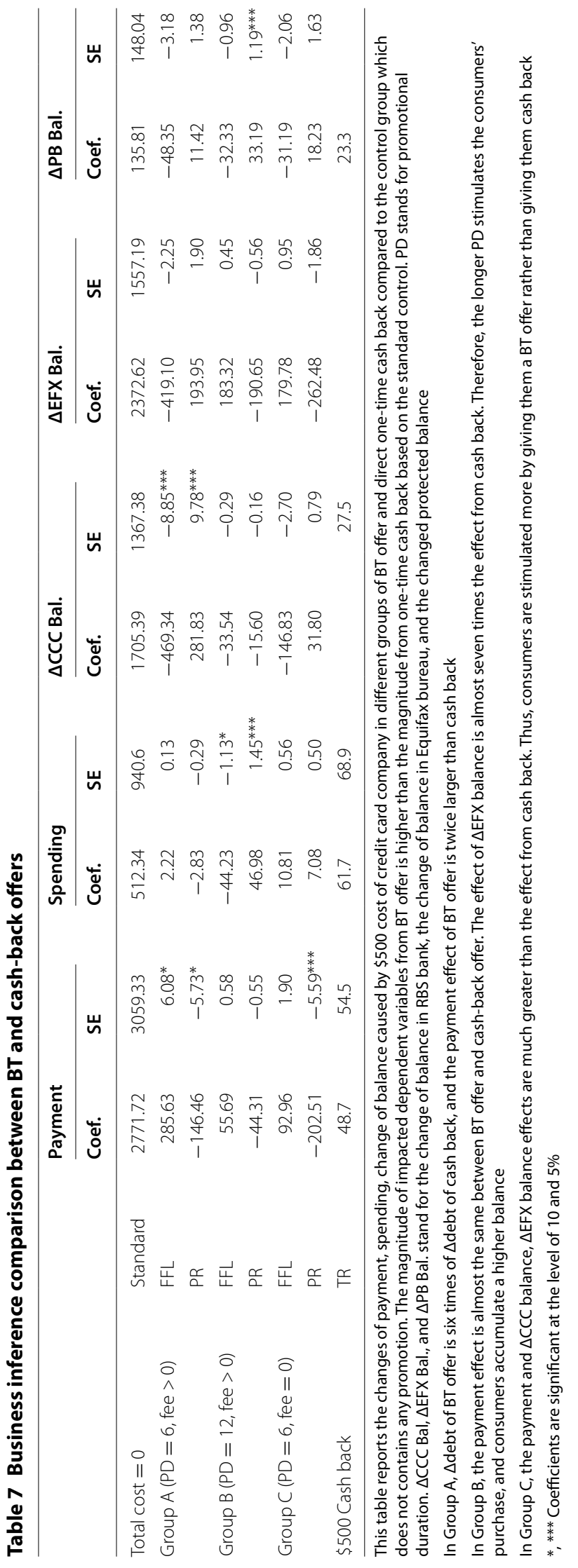


back, especially for FFL offer. It is because a limitation of the data for spending. Since there is no total spending, the spending shown here only stands for spending in the study bank.

In the second offer group (B), due to the $\$ 859.24$ total cost, all effects should be adjusted to the $\$ 500$ level. Then, the payment effect is nearly the same as the cash back. The spending effect is still smaller, but considering the spending is just in the examined bank, its effect should be larger than the spending from the cash-back offer. The large difference with the baseline group (A) exists in $\triangle \mathrm{CCC}$ balance. That is, $\triangle \mathrm{CCC}$ balance is smaller than the effect of cash back. However, the effect of $\triangle \mathrm{PB}$ balance considerably improves after adjustment is higher than cash back. The effect of $\triangle \mathrm{EFX}$ balance is almost seven times the effect from cash back. The longer PD stimulates the consumers' purchase, and consumers accumulate a higher balance.

In the third group (C), adjusting the total cost to $\$ 500$, the payment, and $\triangle \mathrm{CCC}$ balance, $\triangle E F X$ balance effects are much greater. Based on the standard finance condition of consumers, cash back can change $1 \%$, at most $2 \%$ of their short-term finance, but a BT offer changes consumers' finance from 8 to $27.5 \%$. Hence, the evidence confirms the result found in their paper that consumers originally save more cash in their accounts rather than purchase more. However, this does not hold for spending. Due to the limitations of our data, spending is not equal to total purchase. Thus, to some extent, the data are not comparable. This study considers that consumers are stimulated more by giving them the BT rather than giving them cash back. The credit card company can design more BT offers instead of cash back to encourage consumers to borrow and change their short-term finance.

\section{Conclusion}

This study used a unique randomized dataset of credit card accounts to analyze customers' short-term finance behavior in response to BT offers. We first estimated consumers' choices based on a multinomial choice model, so finding that the two interest rates gave the largest impact on consumers' choices. Consumers carrying high balances tend to accept the FFL offers, while consumers with good credit records and with low utilization ratios of their cards tended to accept PR offers. This result was confirmed from estimation. Then, this study estimated the total effect and monthly effects of payment, spending, $\triangle \mathrm{CCC}$ balance, $\triangle \mathrm{EFX}$ balance, and $\triangle \mathrm{PB}$ balance.

Our findings are summarized in such a manner that the outcome variable decreases with the increase in FFL rate and increases with the increase in the PR. The contradiction effect of customers for the PR offer may occur because customers like to accept the BT offer with zero in PR, and the take-up rate of the PR offer decreases when the PR increases. In the baseline offer group (A), the offer significantly impacts customers' behavior in the examined bank. As for the 12-month promotion duration group (B), the paths of coefficients are smoothly changed, and the effects for spending and $\triangle \mathrm{PB}$ balance become more significant. Customers spend less if they receive a high FFL offer, and they spend even more if they receive a high PR offer. Consumers may take advantage of the PR offer, consume more, and then accumulate more debt. On the other hand, consumers pay off the high-interest debt with an increased FFL rate. They can also use other banks' offers to pay off the debt in the examined bank. The last offer group (C) with the 6-month duration and zero maximum fee implies that customers are impacted more in their aggregate debt levels but not in the 
debt they hold in the examined bank. They decrease their aggregate debt levels with an increased PR and increase their aggregate debt levels with an increased FFL rate.

Finally, from a financial perspective, this study has implemented counterfactual analysis to compare payment, spending, and $\Delta$ Debt effects between the BT offer and the cash-back offer, controlling the total cost at the same level. Both effects of BT offer and cash-back offer are compared to one control group-standard finance condition of consumers without any promotion. Then not only absolute amount of change but also relative amount of change from two offers can be summarized. This study finds that credit card companies should stimulate consumers' short-term finance by offering a BT offer rather than a cash-back offer.

Even though the sample size of this randomized data is huge with 66,222 observations, the period only covers 14 months. This is a drawback of the analysis, which is limited by the data resource. The data will be extended and analyzed in the future to find whether there is different or new result.

In conclusion, it is hoped that this study makes a contribution in research on credit card business. We look forward to seeing future research extensions of this study.

\section{Authors' contributions}

YY is the first and corresponding author. She collected the data and did the analysis. YY also wrote this manuscript. TS gave some suggestions to the analysis and revised the manuscript. Both authors read and approved the final manuscript.

Competing interests

There is no financial or non-financial competing interest in relation to this work.

\section{Publisher's Note}

Springer Nature remains neutral with regard to jurisdictional claims in published maps and institutional affiliations.

Received: 23 December 2016 Accepted: 28 February 2017

Published online: 16 March 2017

\section{References}

Agarwal S, Chomsisengphet S, Liu C, Souleles NS (2006) Do consumers choose the right credit contracts? University of Pennsylvania, Wharton School, Mimeo

Agarwal S, Liu C, Souleles NS (2007) The reaction of consumer spending and debt to tax rebates-evidence from consumer credit data. J Polit Econ 115(6):986-1019

Ausubel LM (1991) The failure of competition in the credit card market. Am Econ Rev 81(1):50-81

Ausubel LM (1999) Adverse selection in the credit card market. Working paper, Department of Economics, University of Maryland

Bar-llan A, Blinder AS (1988) The life cycle permanent-income model and consumer durables. Annales d'Economie et de Statisticque 9:71-91

Calem P, Mester L (1995) Consumer behavior and the stickiness of credit card interest rates. Am Econ Rev 85(5):1327-1336

Calem PS, Gordy MB, Mester LJ (2006) Switching costs and adverse selection in the market for credit cards: new evidence. J Bank Financ 30(6):1653-1685

Della Vigna S, Malmendier U (2006) Paying not to go to the gym. Am Econ Rev 96(3):694-719

Du RY, Kamakura WA (2008) Where did all that Money Go? Understanding how consumers allocate their consumption budget. J Market 72(6):109-131

Elaydi R, Harrison C (2010) Strategic motivations and choice in subsistence markets. J Bus Res 63(6):651-655

Gentzkow M (2007) Valuing new goods in a model with complementarity: online newspaper. Am Econ Rev 97(3):713-744

Gross D, Souleles N (2002) Do liquidity constraints and interest rates matter for consumer behavior? Evidence from credit card data. Q J Econ 117(1):149-185

Gross T, Notowidigdo M, Wang J (2012) Liquidity constraints and consumer bankruptcy: evidence from tax rebates. NBER working paper

Hendel I (1999) Estimating multiple-discrete choice models: an application to computerization returns. Rev Econ Stud 66(2):423-446

Hendel I, Lizzeri A (1999) Adverse selection in durable goods market. Am Econ Rev 89(5):1097-1115

Jappelli T (1990) Who is credit constrained in the U. S. economy? Q J Econ 105(1):219-234 
Laibson DI, Repetto A, Tobacman J (2007) Estimating discount functions with consumption choices over the lifecycle. NBER working paper no. 13314

Miravete EJ (2003) Choosing the wrong calling plan? Ignorance and learning. Am Econ Rev 93(1):297-310

Musto DK, Souleles NS (2006) A portfolio view of consumer credit. J Monet Econ 53 1:59-84

Narayanan S, Chintagunta PK, Miravete EJ (2007) The role of self selection, usage uncertainty and learning in the demand for local telephone service. Quant Market Econ 5:1-34

Nevo A (2011) Empirical models of consumer behavior. Ann Rev Econ 3:51-75

Papies D, Eggers F, Wlomert N (2011) Music for free? How free ad-funded downloads affect consumer choice. J Acad Mark Sci 39:777-794

Scholnick B, Massoud N, Saunders A (2013) The impact of wealth on financial mistakes: evidence from credit card nonpayment. J Financ Stab 9:26-37

Shimp TA, Moody MP (2000) In search of a theoretical explanation for the credit card effect. J Bus Res 48:17-23

Shui H, Ausubel L (2004) Time inconsistency in the credit card market. University of Maryland, Mimeo

\section{Submit your manuscript to a SpringerOpen ${ }^{\mathcal{O}}$} journal and benefit from:

- Convenient online submission

\section{- Rigorous peer review}

Immediate publication on acceptance

Open access: articles freely available online

- High visibility within the field

- Retaining the copyright to your article

Submit your next manuscript at $\boldsymbol{\nabla}$ springeropen.com 